\title{
SHEAR BANDING IN DRAINED AND UNDRAINED TRIAXIAL TESTS ON A SATURATED SANDSTONE ; POROSITY AND PERMEABILITY EVOLUTION
}

J. Sulem*, CERMES - Ecole Nationale des Ponts et Chaussées / LCPC, Institut Navier, France

H. Ouffroukh, CERMES - Ecole Nationale des Ponts et Chaussées / LCPC, Institut Navier, France

\begin{abstract}
Detailed analysis of shear band formation and shear band microstructure formed in drained and undrained triaxial tests on Fontainebleau sandstone is presented. It is shown that under globally undrained conditions, local fluid exchanges inside the sample occur at shear banding resulting into an heterogeneous damage pattern along the shear band. At high confinement, pore pressure generation inside the band leads locally to fluidisation of the crushed material which results into the formation of connected channels in the heart of the band. Image processing analysis is used for evaluation of porosity inside the shear band and estimation of the permeability is performed using the Walsh and Brace [26] model. It is shown that, porosity increase as observed in the band at low confining pressure and porosity decrease as observed at high confining pressure are both accompanied by a reduction of permeability inside the shear band due to the increase of tortuosity and specific surface. However, this permeability reduction is much more important at high confining pressure and can reach values three orders of magnitude smaller than the permeability of the intact material.
\end{abstract}

Keywords: Sandstone, shear-band, porosity, permeability, image analysis

published in: International Journal of Rock Mechanics and Mining Sciences, 43, 2006, 293-310

\footnotetext{
* Corresponding author.
}

Postal address : CERMES, Ecole Nationale des Ponts et Chaussées, 6 et 8 avenue Blaise Pascal, Cité Descartes, Champs-sur-Marne, 77455, Marne-La-Vallée, cedex 2, France.

Phone : 331641535 45, Fax : + 331641535 62, Email : sulem@cermes.enpc.fr 


\section{Introduction}

Transport properties of porous rocks such as permeability are strongly influenced by the deformation process and controlled by the evolution of the structure of the grain geometry and the pore space (volume, connectivity, tortuosity, shape, etc.). Shear bands which in brittle rocks are zones of localised intense damage appear as weaker than the surrounding rock. Depending on the initial porosity of the rock and on the stress level, compaction and strainhardening or, on the contrary, dilation and strain softening may occur. In the last decade important experimental and theoretical studies have been made in this area for understanding deformation mechanisms and permeability evolution in granular rocks [1-15]. Shear localisation results from the coalescence near the peak stress of clusters of oriented microcracks due to Hertzian fractures initiated at grain contacts.

For rocks with a relatively large porosity $(>10 \%)$ under hydrostatic loading, it has been identified by many authors (e.g. Brace, [16], Zhang et al. [17]) that the volumetric strain curve exhibits an inflection point for a stress of several hundreds of MPa beyond which an important inelastic volumetric compaction occurs. Microstructural observations show that significant grain crushing and pore collapse is associated with the inelastic compaction. The high density of cracks in the shear band is comparable with that of samples 'homogeneously' deformed in the cataclastic flow regime. Detailed observation of shear zones may thus give clues to understand the behaviour of rocks at large stress when pore collapse and grain crushing are important.

A challenging issue is the modelling of grain crushing phenomenon and its influence on the hydro-mechanical properties. Grain crushability can be included in the modelling procedure using discrete element analysis $[18,19]$. Discrete element models can mimic the macroscopic behaviour of real including elasticity, anisotropic damage, post-peak softening [20-22]. However up to now these models do not consider the influence of the evolution of the 
microstructure in due course of the deformation process on the hydro-mechanical properties of the rock. More recently a continuous approach including a degradation law for the rock skeleton was proposed by Yuan and Harrison [23] in order to account for the effect of porosity evolution on the permeability.

In a previous paper [24] the porosity change of shear bands formed in dry samples of Fontainebleau sandstone of initial porosity of $21 \%$ tested in triaxial compression has been analysed using a simple evaluation technique. This technique was based on the concept of linear porosity applied to microphotographs of the shear zone. It was shown that for specimens tested under relatively low confining pressure $(7 \mathrm{MPa})$, the porosity increases up to about $30 \%$ inside the band and decreases rapidly towards the initial value outside the band. This was interpreted as dilating shear banding at low confining pressure. For specimens tested under relatively high confining pressure (28 MPa), a different patterning was observed. A compacting zone with high grain crushing and low porosity (values between 2 and $19 \%$ ) is observed in the centre of the band. This zone is surrounded by a dilating one with grain cracking and high porosity (up to $36 \%$ ). However as mentioned in this paper, this simple technique is time consuming and tedious, and cannot be used for systematic analysis of a large data base.

In the present study the same rock (Fontainebleau sandstone) is used and geometrical characteristics of the shear band (porosity, specific surface, grain size) are evaluated by using image processing software. The previous study is also extended to fluid saturated samples tested in drained and undrained conditions. The influence of the fluid and of the drainage conditions on shear band formation and shear band microstructure is carefully examined. Several authors have used image analysis of the pore structure of sandstone for predicting the permeability (e.g. Lock et. al [25]). Usually these models are based on a reconstruction of a network of connected conductors which requires the knowledge of the geometrical properties 
of the pores. The approach that we use here is more empirical. The permeability model of Walsh and Brace [26] is used to correlate porosity and permeability.

\section{Experimental setting}

A triaxial cell with internal diameter of $140 \mathrm{~mm}$ is used (Fig.1). This cell can sustain a confining pressure up to $60 \mathrm{MPa}$. It contents a system of hydraulic self-compensated piston. The loading piston is then equilibrated during the confining pressure builds up and directly applies the deviatoric stress. The axial and radial strains are measured directly on the sample inside the cell with two axial transducers and four radial ones of LVDT type (see section AA on Fig. 1 and Fig. 2). These internal devices allow to avoid the main errors of strain measurements of devices external to the cell such as the compliance of the loading device, the tilting of the specimen, the bedding errors at the ends of the specimen. This device is also more adequate that strain gages which are currently used for strain measurements on rocks. Strain gages can perturb the porous specimen because of glue penetration inside the sample and are useless beyond the onset of strain localisation. A correction for the radial deformation of the membrane during the test has been calibrated. The lower base of the cell is equipped with a pore pressure transducer. Pore pressure measurements during test are then performed very close to the sample base. The confining pressure is applied by a servo controlled high pressure generator which consists of a piston moving in a pressure chamber. The pressure generator is guided by an electronic regulator receiving an analogical signal from an external transducer. The regulators are programmed by a PC computer.

Axisymmetric strained-controlled compression tests in drained and undrained conditions have been performed on Fontainebleau sandstone at various confining pressures (7, 14, 28, 40 and $50 \mathrm{MPa}$ ). The axial displacement is servo-controlled via the internal radial transducers at a rate corresponding to a constant radial strain rate of $10^{-5} \mathrm{sec}^{-1}$ which is slow enough to insure fully drained deformation. The servo-control system allows to control failure and post-peak 
behaviour when the control parameters have been optimised for a fast response of the system [27]. The choice of the radial displacement as the control variable is made because this quantity is increasing rapidly with the axial stress close to the peak. The loading rate is thus actually very slow close to the peak strength. The tests have been stopped close after the maximum axial load has been reached in order to keep the samples in a state as close as possible to the shear band initiation and observe the bands after the tests with an electron scanning microscope as described in section 4. In order to make good observation it is important to obtain at the end of the test a specimen with one or several bands clearly formed but without any material discontinuity. Failure along a unique shear band is actually obtained for confined tests at low confining pressure and eventually along several bands for tests at high confining pressure. The interface between the rock specimen and the loading platens of the testing machine is lubricated to avoid friction [28-30]. Cylindrical specimens with a diameter of $37.5 \mathrm{~mm}$ and a height of $77 \mathrm{~mm}$ are used.

The rock chosen for this study is the Fontainebleau sandstone with a porosity of $21 \%$. It is a uniformly graded rock with a grain size of $0.25 \mathrm{~mm}$ (Fig. 3). Its composition is $98 \%$ quartz.

\section{Experimental results}

\subsection{Stress-Strain response}

In the range of confining pressures used in our tests the behaviour of Fontainebleau sandstone is rather brittle. The tests have been stopped just after the peak of axial load. The corresponding axial strain is around $0.5 \%$ for low confining pressure and $1 \%$ for higher ones. The overall stress-strain response is presented on Fig. 4 for drained tests and on Fig. 5 for undrained tests. We observe that for the undrained test at $7 \mathrm{MPa}$ of confining pressure, the axial strain is decreasing after the peak whereas the radial strain is always increasing (Fig. 5a). 
As explained above, the radial displacement is actually the control variable of the system and it is increased at constant rate. The decrease of the axial displacement after the peak stress as measured by the transducers reflects the strain localisation process. When shear banding occurs the strain field is not homogeneous inside the sample and rigid block sliding along the shear surface can occur.

Use is made here of the Terzaghi effective stress concept. Note that due to the fact that the fluid compressibility $\left(4.0^{*} 10^{-4} \mathrm{MPa}^{-1}\right.$ at $\left.20^{\circ} \mathrm{C}\right)$ and the quartz grain compressibility $\left(2.75^{*} 10^{-5}\right.$ $\left.\mathrm{MPa}^{-1}\right)$ are comparable to the saturated rock compressibility $\left(10^{-4} \mathrm{MPa}^{-1}\right)$, undrained tests are not isochoric (i.e. at constant volume) as in classical Soils Mechanics (Fig. 5b). The maximum effective stress is increasing with effective confining pressure. On these graphs, negative (respectively positive) volumetric strains correspond to contractant (respectively dilatant) behaviour. The samples undergo initial compaction and then dilatant strain hardening. The contractant phase is less pronounced for undrained tests due to pore pressure generation.

The experimental results for drained and undrained tests on saturated samples are consistent with those presented in [24] for dry samples (Fig. 6). The effective yield stress can be fitted with a linear Mohr-Coulomb criterion which in case of axisymmetric compression is written as

$$
\sigma_{\text {axial }}^{\prime}=2 \mathrm{Ctan}(\pi / 4+\phi / 2)+\sigma_{\text {radial }}^{\prime} \tan ^{2}(\pi / 4+\phi / 2)
$$

with

$$
\mathrm{C}=15.5 \mathrm{MPa} \text { and } \phi=41.3^{\circ} \text {. }
$$

\subsection{Pore pressure generation in undrained tests}

The generated pore-pressure in undrained tests is plotted versus the axial strain for the various confining pressures on Fig. 5c. The magnitude of the induced pore pressure in the contractant phase depends upon the porosity of the rock, the drained compressibility of rock, and the 
compressibilities of the pore fluid and rock grains as described in [31]. Theses curves are consistent with the volumetric response of the samples (Fig. 5b). They exhibit a maximum at the contractance-dilatance transition. Dilatancy is caused by the formation and extension of open microcracks which results in pore pressure dissipation. The maximum of the generated pore pressure increases with increasing confining pressure. At low confining pressures ( 7 and $14 \mathrm{MPa}$ ) the pore pressure at yield effective stress is lower than the initially applied back pressure. Such cavitation phenomenon has been observed for dense sand [32] and for sandstone under low confining pressure [33].

\subsection{Shear band formation}

For all the tests in drained and undrained conditions, the specimens failed with the formation of one or several shear bands. In most experiments it was possible to control the post-peak behaviour and the unloading phase of the sample in order to avoid the formation of a discontinuity surface. These shear bands are clearly visible on the surface of the sample. The zone of localised failure is clearly identified due to the white coloration of the band visible to the naked eye (Fig. 7). Similar coloration of the shear zone in sandstone was observed by Ord et al. [13], Bésuelle et al.[12], Mair et al.[9], El Bied et al [24]. This colour change is due to the crushing of quartz grains and allows for a precise evaluation of the thickness and the orientation of the shear band.

Extensive presentation of shear band analysis in geomaterials can be found in Vardoulakis and Sulem [34]. In globally undrained conditions, the heterogeneity of the damage pattern at shear banding as it will be presented in the next section, allows for local fluid exchanges. This means in turn that the heterogeneous development of micro-fractures in a granular rock during deviatoric loading leads to local drainage of the pore fluid. As shown in Vardoulakis [35, 36] (see also Vardoulakis and Sulem [34]), the possibility of locally undrained shear banding is 
excluded as this situation would induce pore-water pressure shocks across the shear band boundaries.

The onset of shear banding has been studied experimentally using the independent axial and lateral displacement measurements on the specimen. Detection is performed by comparing the two axial strain measurements and/or the four radial strain measurements. The difference between the measurements of two opposite points is plotted versus the applied axial strain as shown for example on Fig. 8. This difference is very small and almost constant as long as the deformation is reasonably homogeneous inside the sample but diverges rapidly at some critical point corresponding to the threshold of loss of homogeneous deformation. This point indicate the limit after which the response of the specimen cannot be considered as representative of the material behaviour but as a structural response of a system. Without precise monitoring of the displacement field inside the sample during the test using visualisation techniques it is not possible to know if this point is the onset of the coalescence of localised damage zones or the onset of movement along a through-going shear band.

On Fig. 8 corresponding to a drained test at $28 \mathrm{MPa}$ of confinement, the points of divergence for axial and radial strain measurements (points $\mathrm{C}_{1}$ and $\mathrm{C}_{2}$ respectively) are almost simultaneous and are compared with the threshold of contractant/dilatant behaviour (point B) and the point of loss of linearity of the axial strain-axial stress response (point A). Similar technique for the detection of strain localisation has been used by Santarelli [37], Tatsuoka and Kim [38], Bésuelle et al [12]. The results for all the tests are shown on Fig. 9. The axial and the radial measurements give in general similar results. The loss of homogeneous deformation occurs before the peak and is delayed at higher confining pressure in globally undrained conditions. On Fig. 10, the threshold from contractant to dilatant behaviour is compared with the onset of localisation for drained and undrained tests. This graphs shows that for drained tests the transition from contractant to dilatant behaviour which corresponds 
to the initiation of microcracking occurs close before the onset of localisation. For undrained tests, due to the effect of pore pressure generation, the transition from contractant to dilatant behaviour occurs much earlier than for drained tests and is increasing for higher confining pressure. These two thresholds are observed not only for sandstones but also for crystalline rocks with the crack initiation and crack damage thresholds as defined for example for granite $[39,40]$.

The orientation of the shear band is measured on the central part of the specimen, as the shear band is often deviated close to the extremities of it. The measured orientation of the shear band with respect to the minor (in absolute value) principal stress axis is presented on Table 1. These results show that the orientation of the shear band decreases when the effective confinement pressure increases as commonly observed (e.g. [12, 24]). This can be explained by the pressure sensitivity of granular rocks for which the mobilised friction angle and dilatancy angle decrease with increasing effective mean stress. The difference observed in the shear band orientation between drained and undrained tests is due to the fact that in Table 1, the total confining pressure is referenced. As shown in the following, in terms of effective confining pressure, the results for undrained tests are consistent with those of drained ones (Fig. 12).

Strain localisation in the form of a shear band corresponds to weak discontinuities for the incremental displacement and occurs first when the acoustic tensor $\Gamma$ becomes singular [41]:

$$
\operatorname{det}\left(\Gamma_{\mathrm{ij}}\right)=0, \text { with } \Gamma_{\mathrm{ij}}=\mathrm{L}_{\mathrm{ijkl}} \mathrm{n}_{\mathrm{k}} \mathrm{n}_{1}
$$

where $\mathbf{L}$ is the incremental constitutive tensor of the material and $n_{i}$ are the cosines of the normal to the shear band.

As shown in Vardoulakis and Sulem [34], the shear band orientation $\theta_{\mathrm{B}}$ with respect to the major (in absolute value) principal stress axis can be approximated by a simple formula which was first proposed by Arthur et al [42] on the basis of experimental observations and 
subsequently proven theoretically and supported experimentally by Vardoulakis [43] for biaxial tests

$$
\theta_{\mathrm{B}}=45^{\circ}+\phi / 4+\psi / 4
$$

where $\phi$ is the friction angle and $\psi$ is the dilatancy angle at the onset of strain localisation. In a simple analysis it is assumed that shear banding occurs at maximum deviatoric stress corresponding to a mobilised friction angle of $41.3^{\circ}$. The dilatancy angle is evaluated on experimental data at various effective stress. For drained and undrained tests, it is found that the dilatancy angle at peak stress evolves in a consistent manner with the effective confining pressure. According the data are fitted with the following linear relation (Fig. 11):

$$
\psi(\text { in degrees })=-0.76 \sigma_{\text {rad }}^{\prime}(\text { in } \mathrm{MPa})+48.3
$$

where $\sigma^{\prime}$ rad is the effective radial stress expressed in MPa.

As shown on Fig. 12a the Arthur's formula gives an acceptable evolution of the shear band inclination with respect to the effective confining pressure.

Remark: For our tests in the range of confining pressures used, the maximum mobilised friction angle was found to be independent of the confining pressure and equal to 41.3. The classical Mohr-Coulomb solution for the orientation of the failure plane is $45^{\circ}+\phi / 2=65.65^{\circ}$. The Coulomb solution cannot reflect the decrease of the shear band orientation with confining pressure. We show here the important effect of the dilatancy angle on the shear band orientation.

A more precise evaluation of the shear band orientation can be obtained by performing a complete a complete strain localisation analysis which gives good predictions of the shear band inclination (Fig. 12b). The analysis is presented in Appendix. 


\section{Microstructural observations}

\subsection{Sample preparation}

As explained in section 2, the test is stopped close after the peak strength. A good control of the post-peak phase allows to avoid a violent failure of the sample. Therefore the sample shows a clear shear band but no material discontinuity.

At the end of the compression test, each sample is carefully removed from the loading cell while still encased in its rubber sleeve and put into a vacuum bell-jar where it is impregnated with epoxy resin. A plane cutting of the specimen allows a clear observation of the shear band inside the rock to evaluate its thickness and orientation. A metallization is performed by pulverising gold. This operation allows better observations with the electron scanning microscope. Examples of microphotographs of the shear band zone are presented for an undrained test under $7 \mathrm{MPa}$ of confining pressure (Fig. 13) and a drained test under $50 \mathrm{MPa}$ of confining pressure (Fig. 14).

\subsection{Image analysis software}

Image analysis is nowadays currently used to study rock microstructure (e.g. [2, 3, 25, 4446]). It is of major importance to have a good resolution of the input image and a good tuning of the contrast and of the threshold of grey level to discriminate between solids and voids and obtain reliable image analysis results. In this study the image analysis software 'IMAQVISION Builder 6' of National Instruments is used. Each image taken from the electron scanning microscope is represented by a grey level matrix with values between 0 and 255 . A binary image is built by the choice of a threshold for the grey level which attributes the value 0 for voids and 1 for the solid phase. The proper choice of this threshold as well as the good resolution of the original image are key points to obtain good results in computer-aided image analysis. The ratio of magnification is chosen for each micrograph and the threshold of the 
grey level is first calibrated for each image by analysing the grey level histogram and by comparing the binary image and the original one (Fig 15). In particular one must insure that the small particles are not lost or clustered which are the main sources of inaccuracies for porosity evaluation. The binary image is then analysed for the determination of the porosity, the specific surface, the orientation and the size of the particles.

This technique was first applied to intact Fontainebleau sandstone specimens with different porosities between 7 and $20 \%$. The results of the image analysis have been compared to the ones obtained from classical experimental porosity determination such as water imbibation and mercury intrusion (Table 2). They show a good agreement between the experimental technique and the image analysis determination. The specific surface is the pore surface area per unit volume. Image analysis of the intact Fontainebleau sandstone specimens is used to evaluate this quantity. The results have been compared to those published by Fredrich et al [44] for Fontainebleau sandstone specimens with similar porosity and have also shown good agreement (Table 3).

\subsection{Image analysis of shear zones}

The structure of the shear zones for the specimens tested at relatively low confining pressure (7 and $14 \mathrm{MPa}$ ) are similar for drained and undrained tests (Figs. 13 and 16). The shear band thickness is comprised between 200 and $500 \mu \mathrm{m}$ i.e. one to two intact grain size. Inside the band the grains are broken with little localised crushing.

For the specimens tested in drained conditions under higher confining pressure $(28,40$ and 50 $\mathrm{MPa}$ ) the shear band is characterised by intense grain crushing and pulverisation (Fig. 17). Major changes in the grain size distribution is clearly visible. Very small particles with size of the order of micrometer are produced. The fragments are densely packed, which gives an aspect of flour or white powder visible to the naked eye. Similar observations have been made for dry specimens of Fontainebleau sandstone [24]. 
For specimens tested in undrained conditions under high confining pressure $(28,40,50 \mathrm{MPa})$ the structure of the shear zone is quite heterogeneous with zones of compaction (as in the drained tests) and zones of dilation (Fig. 18). This heterogeneity can be related to the heterogeneity of the pore pressure generated during the loading of the sample. This results into local fluid exchanges between compacting zones that expel fluid and dilating ones that absorb it. The observations demonstrate also that, although no fluid exchanges is allowed between the sample and the exterior of the system during globally undrained tests, local fluid exchanges inside the sample occur at shear banding resulting into an heterogeneous damage pattern along the shear band. At high confinement, pore pressure generation inside the band leads locally to fluidisation of the crushed material which results into the formation of connected channels in the heart of the band (Fig. 19). On Fig. 19b one can clearly observe that the fines are accumulating along the boundary of the shear band and form a clogged zone of clustered fines. In our understanding the observed channels in undrained tests cannot be attributed to the formation of open fractures during unloading or resin impregnation process as such features are not observed in samples tested in drained conditions.

Outside the shear band, near the limits of the shear band, the grains are cracked but not crushed. The cracking phenomenon decreases rapidly outside the band.

From image analysis processing, the porosity of the material is evaluated at various places inside and outside the shear band. Inside the shear zones, the grain size distribution of the rock and the pore space are heterogeneous. Therefore the analysis is performed on ten different images taken at various locations along a parallel to the shear band axis. The porosity is evaluated for each image and the mean value is calculated. The size of each image on which the porosity is evaluated is about 20 intact grain size which can be considered as a representative element. An example of an image on which the porosity is calculated is shown on Fig. 20. This micrograph is a magnification of a zone of Fig. 17.a. In a previous paper [24], 
the evolution of the grain size distribution inside the band was discussed. For example, it was shown that, for the specimen tested under $28 \mathrm{MPa}, 74 \%$ of the particles have a size smaller than $\mathrm{D}_{50} / 10$ and $26 \%$ have a size comprised between $\mathrm{D}_{50} / 10$ and $\mathrm{D}_{50}$. These numbers show that the dominant effect is here pulverisation of the grains. The smallest grain size observed is $1 \mu \mathrm{m}$. Only few grains are simply fractured. All grain size measurements are smaller that $\mathrm{D}_{50}$. For the permeability evaluation proposed in section 4, the permeability model of Walsh and Brace [26] used here does not include explicitly the grain size of the rock. The only geometric quantities involved are the porosity and the specific surface.

The results of the evaluation of the porosity inside the bands are shown on Fig. 21a for the drained tests and on Fig. $21 \mathrm{~b}$ for the undrained tests. As in the undrained tests at high confining pressure it was observed that the structure of the band is heterogeneous with zones of dilation and zones of contraction, porosity evaluation on these specimens has been preferably performed on the compacting zones. The average porosity inside the band is plotted versus the confining pressure for drained and undrained tests on Fig. 22. For each confining pressure the two values are very close. A sharp transition occurs for a critical confining pressure of about $20 \mathrm{MPa}$. At lower confining pressure that this critical value, the porosity inside the band is higher that the one of the original sample (here $21 \%$ ). For higher ones it is smaller and reaches a value of about $10 \%$ for tests at $50 \mathrm{MPa}$ of confinement.

\subsection{Permeability model}

It is known that there is no unique relationship between porosity and permeability applicable to all porous media and that the geological evolution process of the pore space influence the permeability-porosity relationship (e.g. [11]). In classical permeability models such as the Carman-Kozeny model, the permeability is related to pore geometry parameters, i.e. porosity, hydraulic radius, tortuosity and specific surface. For the Fontainebleau sandstone, it was shown by Fredrich et al [47] that the observed bench permeabilities for samples with 
porosities between 10 and $20 \%$ agree well with those using the equivalent channel model of Walsh and Brace [26] with the following expression for the permeability $\mathrm{k}$

$$
\mathrm{k}=\left(\frac{\mathrm{n}}{\mathrm{S}_{\mathrm{v}}}\right)^{2} \frac{1}{\mathrm{Fb}}
$$

where $\mathrm{S}_{\mathrm{v}}$ is the specific surface, $\mathrm{n}$ the porosity, $\mathrm{b}$ is a shape factor and $\mathrm{F}$ is a formation factor given by

$$
\mathrm{F}=\frac{\tau^{2}}{\mathrm{n}}=\frac{\rho}{\rho_{\mathrm{f}}}
$$

In the above expression for the formation factor $F, \tau^{2}$ is the tortuosity and $\rho$ and $\rho_{\mathrm{f}}$ are the resistivities of the saturated rock and of the fluid respectively. The shape factor $b$ is equal to 2 for circular tubes and equal to 3 for cracks. The Archie [48] law is used to approximate the formation factor

$$
\mathrm{F}=\frac{\rho}{\rho_{\mathrm{f}}}=\frac{\mathrm{a}}{\mathrm{n}^{\mathrm{m}}}
$$

where $\mathrm{m}$ is the cementation factor and $\mathrm{a}$ is a pore geometry coefficient.

Data published in the literature on measurements of pore geometry characteristics and transport properties of Fontainebleau sandstone samples of various porosities by Bourbié and Zinsner [49], David and Darot [50], Fredrich et al [47] have been used to calibrate the various parameters of the Walsh and Brace [26] model.

The two parameters a and $\mathrm{m}$ are calibrated on data from [47] and [50]. The results are shown on Fig. 23. The following values have been found: $\mathrm{a}=1.844, \mathrm{~m}=1.427$.

On the basis of a large data base of 240 samples of Fontainebleau sandstone with various porosities, Bourbié and Zinsner [49] have proposed a power law relationship between the porosity and the air-permeability 


$$
\begin{aligned}
& \mathrm{k}(\mathrm{mDarcy})=0.303 \mathrm{n}^{3.05} \text { for } \mathrm{n}>8-9 \% \\
& \text { and } \mathrm{k}(\mathrm{mDarcy})=2.75 * 10^{-5} \mathrm{n}^{7.33} \text { for } \mathrm{n}<8-9 \%
\end{aligned}
$$

The evaluation of permeability on image analysis of intact samples has been performed using the equation (6-8) with $b=2$ and $b=3$ and compared to the power law relationship (9). The results are shown on Fig. 24. The evaluated permeability reproduce correctly the data of Bourbier and Zinsner [49]. These results validate the calibration procedure.

From the evaluation of porosity and specific surface inside the bands of our samples, the permeability has been estimated using the Walsh and Brace model with the above values of the parameters. The results are shown on Fig. 25 for drained tests and on Fig. 26 for undrained tests. In both case the value $b=2$ is assumed. They are similar for drained and undrained tests. For high confining pressure with a compacted shear band, the porosity reduction is accompanied by an important permeability reduction of more than 3 orders of magnitude. For low confining pressure with a dilatant shear band, the porosity increase is accompanied also with a decrease of the permeability of 1 to 2 order of magnitude. This counterintuitive result is due to the fact that despite the increase of porosity, the increase of the specific surface inside the band induces a permeability reduction. Similar observations have been made for sandstones with a porosity higher than $15 \%[5,6]$.

\section{Conclusion}

Transport properties of rocks such as permeability are strongly influenced by the deformation process. On the basis of image analysis, porosity, specific surface and grain-size changes have been studied inside the shear bands formed in triaxial testing on a Fontainebleau sandstone with initial porosity of $21 \%$ under drained and undrained conditions at various confining pressures. 
It is obtained that for specimens tested under relatively low confining pressure ( $7 \mathrm{MPa}$ and 14 $\mathrm{MPa}$ ), the porosity reaches a maximal value of about $30 \%$ inside the band and decreases rapidly towards the initial value of $21 \%$ outside the band. This is interpreted as dilating shear banding at low confining pressure. For specimens tested under high confining pressure $(>25$ $\mathrm{MPa}$ ), a different patterning is observed. A compacting zone with high grain crushing and low porosity is observed in the centre of the band. The porosity reduction is more pronounced at higher confining pressures. From the porosity and specific surface data evaluated from image processing inside the shear zone, the changes in permeability are quantified by using the permeability model of Walsh and Brace [26]. It is shown that, porosity increase as observed in the band at low confining pressure and porosity decrease as observed at high confining pressure are both accompanied by a reduction of permeability inside the shear band due to the increase of tortuosity and specific surface. However, this permeability reduction is much more important at high confining pressure and can reach values three orders of magnitude smaller than the permeability of the intact material.

In globally undrained conditions, similar changes of microstructure of the rock are observed depending on the confining pressure. This results into local fluid exchanges between compacting zones that expel fluid and dilating ones that absorb it. The observations demonstrate also that, although no fluid exchanges is allowed between the sample and the exterior of the system, local fluid exchanges inside the sample occur at shear banding resulting into an heterogeneous damage pattern along the shear band. At high confinement, pore pressure generation inside the band leads locally to fluidisation of the crushed material which results into the formation of connected channels in the heart of the band.

At large scale, similar phenomena are observed in faulted zones when sheared. Usually in fault zones, two main domain can be identified: a fault core of small thickness constituted of highly comminuted ultra-cataclasites is surrounded with a damage zone which consists of 
fractured host rock (e.g [51-53]). The ultracataclastic structure is the results of numerous earthquake ruptures. As shown for example in a recent study of Sulem et al [54] dedicated to the characterisation of Aigion fault material in the Gulf of Corinth (Greece), the permeability of the fault core is very low so that this zone acts as an impervious barrier to transverse fluid flow, whereas the highly fractured damage zone around acts mostly as conduits for nearly along-strike flow. Similar observations can be found in the work of Wibberley and Shimamoto [53].

\section{Acknowledgements}

The authors wish to acknowledge the EU projects DG-Lab Corinth (EVR1-CT-2000-40005) and Fault, Fractures and Fluids: Golf of Corinth, in the framework of program Energy (ENK6-2000-0056) and the 'Groupement de Recherche Corinthe' (GDR 2343), INSU-CNRS for supporting this research. They wish also to thank François Martineau (Laboratoire Central des Ponts et Chaussées) for his assistance in the testing program.

\section{References}

1. Aydin A., Johnson A. M. Analysis of faulting in porous sandstones. .J. Struct. Geol, 1983; 5, No 1: 19-31.

2. Antonellini M.A., Aydin A., Pollard D., Microstructure of deformation bands in porous sandstones at Arches National Park,Utah, .J. Struct. Geol., 1994; 16 Nº7 : 941-959.

3. Menendez, B., Zhu, W., Wong, T.-f., Micromechanics of brittle faulting and cataclastic flow in Berea sandstone, .J. Struct. Geol.,1996, 18, N $1: 1-16$.

4. Wong, T.-f., David, C., Zhu,W., The transition from brittle faulting to cataclastic flow: Mechanical deformation, J. Geophys. Res., 1997, 202 : 3009-3025.

5. Zhu, W., Wong, T.-f., Permeability reduction in a dilatant rock: network modeling of damage and tortuosity, Geophys. Res. Lett., 1996, 23 : 3099-3102.

6. Zhu,W., Wong, T.-f., The transition from brittle faulting to cataclastic flow: Permeability evolution, J. Geophys. Res., 1997, 102 : 3027-3041.

7. Zhu, W., Wong, T.-f., Network modeling of the evolution of permeability and dilatancy in compact rock, J. Geophys. Res., 1999, 104 : 2963-2971.

8. David C., Menendez B., Zhu W., Wong T.F., Mechanical compaction, microstructures and permeability evolution in sandstones. Phys. Chem. Earth (A), 2001, Vol. 26, Nº1-2 : 45-51

9. Mair K., Main I., Elphick S., Sequential growth of deformation bands in the laboratory. J. Struct. Geol, 2000; $22: 25-42$.

10. Main, I.G., K. Mair, O. Kwon, Elphick S.C., Ngwenya B.T., Experimental constraints on the mechanical and hydraulic properties of deformation bands in porous sandstones: a review, in Holdsworth, R.E., Strachan, R.A., Magloughlin, J.F. \& Knipe, R.J. (eds), The nature and significance of fault zone weakening, Geol. Soc. Lond. Spec. Publ., 2001, 186, 43-63. 
11. Bernabé Y., Mok, U. and Evans B., Permeability-porosity relationships in rocks subjected to various evolution process. Pure Appl. Geophys., 2003, 160, 937-960.

12. Bésuelle P., Desrues J., Raynaud S., Experimental characterisation of the localisation phenomenon inside a Vosges sandstone in a triaxial cell. Int. J. Rock Mech. Min. Sci., 2000; 37, 8 : 1223-1237.

13. Ord A., Vardoulakis I., Kajewski R., Shear band formation in Gosford sandstone. Int. J. Rock Mech. Min. Sci. \& Geomech. Abstr, 1991; 28, 5 : 397-409.

14. Ngwenya, B.T., O. Kwon, Elphick S.C., Main I.G., Permeability evolution during progressive development of deformation bands in porous sandstones, J. Geophys. Res., 2003, 108, B7: 2343-2357.

15. Fortin J., Schubnel A., Guégen Y., Elastic wave velocities and permeability evolution during compaction of Bleurswiller sandstone, International Journal of Rock Mechanics and Mining Sciences, 2005, in press.

16. Brace W.F., Volumes changes during fracture and frictional sliding: a review, Pure Appl. Geophys., 1978, $116,603-614$.

17. Zhang J., Wong T-F, Davis D.M., Micromechanics of pressure-induced grain crushing in porous rocks.

18. Cheng, Y. P., Bolton, M. D., Nakata, Y., Crushing and plastic deformation of soils simulated using DEM Géotechnique, 2004, 54, 2, 131-141

19. Tsungui, O., Vallet, D., Charmet J.C., Numerical model of crushing of grains inside two-dimensional granualar materials, Powder Technology, 1999, 190-198

20. Potyondy, D.O., Cundall P.A. A bonded-particle model for rock, International Journal of Rock Mechanics and Mining Sciences, 2004, 41, 1329-1364.

21. Tang. C.A., Liu H., Lee P.K.K., Tsui, Y., Tham, L.G. Numerical tests on micro-macro relation ship of rock failure under uniaxial compression - Part I: effect of heterogeneity, International Journal of Rock Mechanics and Mining Sciences, 2000, 37, 555-569.

22. Tang, C.A., Tham, L.G., Lee, P.K.K., Tsui, Y., Liu, H. Numerical tests on micro-macro relation ship of rock failure under uniaxial compression - Part II: constraint, slenderness and size effect, International Journal of Rock Mechanics and Mining Sciences, 2000, 37, 571-583.

23. Yuan S.C., Harrison, J.P., Modelling, enhanced fluid flow and fault sealing due to fracturing in heterogeneous rock, In : Proc. $11^{\text {th }}$ IACMAG, Barla G. \& M. (eds), 2005, Vol. 2, 301-309.

24. El Bied A., Sulem J., Martineau F, Microstructure of shear zones in Fontainebleau sandstone, International Journal of Rock Mechanics and Mining Sciences, 2002, 39, 7, 917-932.

25. Lock P.A., Jing X., Zimmerman R.W., Predicting the permeability of sandstone from image analysis of pore structure, Journal of Applied Physics, 1002, 92, 10, 6311-6319.

26. Walsh.J.B., Brace. W.F, The effect of pressure on porosity and the transport properties of rock. Journal of Geophy. Res., 1984, 89, N B11, pp 9425-9431.

27. Fairhurst C.A., Hudson J.A., Draft ISRM suggested method for the complete stress-strain curve for intact rock in uniaxial compression. Int. J. Rock Mech. Min. Sci. \& Geomech. Abstr., 1999; 36 : 279-289

28. Labuz J.F., Bridell J.M., Reducing frictional constraint in compression testing through lubrication. Int. J. Rock Mech. Min. Sci. \& Geomech. Abstr., 1993; 30 : 451-455.

29. Papamichos E., Tronvoll J., Skjaestein A., Unander T.E., Labuz J.F., Vardoulakis I., Sulem J., Constitutive testing of a weak sandstone, Mechanics of Cohesive-Frictional Materials, 2000, 5 : 1-40.

30. El Bied A., Sulem J. Adaptation du mode opératoire pour la réalisation d'essais en compression « vraie » sur les roches. Revue française de Géotechnique, 2003, vol. 103, 43-60.

31. Zimmerman R.W., Compressibility of sandstones, 1991, Elsevier.

32. Roger V., Desrues J, Viggiani G., Experiments on strain localisation in dense sand under isochoric conditions. In: Localisation and bifurcation theory for soils and rocks . Oka F eds, Balkema, 1998 : 239-248.

33. Tien.Y.M, Lee.D.H, Juang.C.H, A study on the strain and pore water pressure characteristics of sandstone during repeated loading. In: Key questions in rock mechanics, Cundall et al (eds). 1988 Balkema, Rotterdam: 43-49.

34. Vardoulakis I., Sulem J., Bifurcation Analysis in Geomechanics, 1995, Blackie Academic and Professional 
35. Vardoulakis, I., Deformation of water saturated sand: I. Uniform undrained deformation and shear banding. Géotechnique, 1995a, 46, 441-456.

36. Vardoulakis, I., Deformation of water saturated sand: II. The effect of pore-water flow and shear banding Géotechnique, 1995b, 46,457-472.

37. Santarelli F.J., : Etude expérimentale de la bifurcation dans les roches . Revue Française de géotechnique, $1990,50: 61-70$.

38. Tatsuoka F, Kim Y-S., Deformation of shear zone in sedimentary soft rock observed in triaxial compression. In: Chambon R, Desrues J, Vardoulakis I, editors. Localisation and bifurcation theory for soils and rocks. Rotterdam: Balkema, 1994, : 181-188.

39. Martin C.D., Chandler N.A., The progressive fracture of Lac du Bonnet granite, Int. J. Rock Mech. Min. Sci. \& Geomech. Abstr., 1994; $31:$ 643-659.

40. Diederichs M.S., Kaiser P., Eberhardt E., Damage initiation and propagation in hard rock during tunnelling and the influence of near-face stress rotation, Int. J. Rock Mech. Min. Sci., 2004; 41 : 785-812.

41. Hill, R., Acceleration waves in solids. J. Mech. Phys. Solids, 1962, 10, 1-16.

42. Arthur, J.R.F., Dunstan, T., Al-Ani, Q.A.J., Assadi, A, Plastic deformation and failure in granular media, Géotechnique, 1977, 42, 395-410.

43. Vardoulakis, I., Shear band inclination and shear modulus of sand in biaxial tests. Int. J. Num. Anal. Meth. Geomech., 1980, 4, 3-119.

44. Ioannidis M. A, Kwiecien M. J., Chatzis I., Statistical analysis of the porous microstructure as a method for estimating reservoir permeability . Journal of petroleum science and engineering, 1996, 16 : 251-261.

45. Liang Z., Ioannidas M. A., Chatzis I., Permeability and electrical conductivity of porous media from 3D stochastic replicas of the microstructure . Chemical engineering science, 2000, 55 : 5247-5262

46. Cerepi A, Durand C, Brosse E, Pore microgeometry analysis in low-resistivity sabdstone reservoirs . Journal of petroleum science end engineering, 2002, $35: 205-232$.

47. Fredrich J.T, Greaves K.H Mertin.J.W., Pore geometry and transport properties of Fontainebleau sandstone . Int. J. Rock Mech. Min Sci \& Geomech. Abstr.,1993, 30, 7: 691-697.

48. Archie, G.E., The electrical resistivity log as aid in determining some reservoir characteristics, Trans. Am. Inst. Mech. Eng., 1942, 146, 54-61.

49. Bourbie T., Zinszner B., Hydraulic and acoustic properties as a function of porosity in Fontainebleau sandstone J. Geophys.1 Res., 1985, 90, N. B13: 11524-11532.

50. David C, Darot M., Permeability and conductivity of sandstones. In: Rock at great depth, Maury \& Fourmaintraux (eds). Balkema, Rotterdam, 1989, 203-209.

51. Chester F.M. and Chester J.S., Ultracataclasite structure and friction processes of the Punchbowl fault, San Andreas system, California, Tectonophysics, 1998, 295, 199-221

52. Micarelli, L., Moretti, I., Daniel, J.M. Structural properties of rift-related normal faults: the case study of the Gulf of Corinth, Greece, Journal of Geodynamics, 2003, 36, 275-303.

53. Wibberley, C., Shimamoto, T. Internal structure and permeability of major strike-slip fault zones: the Median Tectonic Line in Mie Prefecture, Southwest Japan, J. Structural Geology, 2003, 25, 59-78.

54. Sulem J., Vardoulakis, I., Ouffroukh H., Perdikatsis V., Thermo-poro-mechanical properties of the Aigion Fault clayey gouge - Application to the analysis of shear heating and fluid pressurization, Soils and Foundations, 2005, 45,2, 97-108. 


\section{Appendix: Shear band analysis of axisymmetric triaxial test}

Extensive presentation of shear band analysis in geomaterials can be found in Vardoulakis and Sulem [34].

The constitutive equations of Mohr-Coulomb flow elastoplasticity theory are used here. In the coordinate system of principal axes of initial stress, the incremental equations are:

$$
\begin{aligned}
& \Delta \sigma_{11}=\mathrm{L}_{11} \Delta \varepsilon_{11}+\mathrm{L}_{12} \Delta \varepsilon_{22} \\
& \Delta \sigma_{22}=\mathrm{L}_{21} \Delta \varepsilon_{11}+\mathrm{L}_{22} \Delta \varepsilon_{22} \\
& \Delta \sigma_{12}=2 \mathrm{G} \Delta \varepsilon_{12}
\end{aligned}
$$

where for axisymmetric compression

$$
\begin{aligned}
& \mathrm{L}_{11}=\mathrm{G}\left((\kappa+4 / 3)-\frac{1}{\mathrm{H}}(1 / \sqrt{3}+\kappa \mathrm{f})(1 / \sqrt{3}+\kappa \mathrm{d})\right) \\
& \mathrm{L}_{12}=\mathrm{G}\left((\kappa-2 / 3)-\frac{1}{\mathrm{H}}(-2 / \sqrt{3}+\kappa \mathrm{f})(1 / \sqrt{3}+\kappa \mathrm{d})\right) \\
& \mathrm{L}_{21}=\mathrm{G}\left((\kappa-2 / 3)-\frac{1}{\mathrm{H}}(1 / \sqrt{3}+\kappa \mathrm{f})(-2 / \sqrt{3}+\kappa \mathrm{d})\right) \\
& \mathrm{L}_{22}=\mathrm{G}\left((\kappa+4 / 3)-\frac{1}{\mathrm{H}}(-2 / \sqrt{3}+\kappa \mathrm{f})(-2 / \sqrt{3}+\kappa \mathrm{d})\right)
\end{aligned}
$$

In equations (A1), $\mathrm{G}$ is the elastic shear modulus, $\kappa=2(1+v) / 3(1-2 v)(v$ is the Poisson's ratio), $\mathrm{H}=1+\mathrm{h}+\mathrm{fi \kappa d}$ is the plastic modulus ( $\mathrm{h}$ is the hardening modulus), $\mathrm{f}$ is the friction coefficient and $d$ is the dilatancy coefficient. These parameters are deduced from the calibration of the elasto-plastic parameters on the triaxial test data.

The characteristic equation for the shear band inclination $\theta$ is

$$
\mathrm{atan}^{4} \theta+\mathrm{b} \tan ^{2} \theta+\mathrm{c}=0
$$

where $\theta$ is measured with respect to the minor principal axis direction and

$$
\begin{aligned}
& \mathrm{a}=\mathrm{L}_{11} \\
& \mathrm{~b}=\left(\mathrm{L}_{11} \mathrm{~L}_{22}+\mathrm{G}^{2}-\left(\mathrm{L}_{12}+\mathrm{G}\right)\left(\mathrm{L}_{21}-\mathrm{G}\right)\right) \\
& \mathrm{c}=\mathrm{L}_{22}
\end{aligned}
$$

The condition for shear band bifurcation is derived from the requirement that the above 
characteristic equation (A3) has real solutions. This condition is firstly met at the state for which

$$
\mathrm{b} / \mathrm{a}<0 \text { and } \Delta=\mathrm{b}^{2}-4 \mathrm{ac}=0
$$

Using the constitutive equations (A2), equation (A5) can be solved explicitly in terms of the critical hardening modulus $\mathrm{h}_{\mathrm{B}}$ at shear banding

$$
\mathrm{h}_{\mathrm{B}}=\frac{1}{4} \kappa \frac{9 \kappa\left(\mathrm{f}^{2}+\mathrm{d}^{2}\right)-2 \mathrm{fd}(15 \kappa+8)-2 \sqrt{3}(\mathrm{f}+\mathrm{d}+\sqrt{3} / 2)(3 \kappa+4)}{9 \kappa^{2}+15 \kappa+4} \text { with } \frac{\mathrm{f}+\mathrm{d}+\sqrt{3}}{3 \kappa(\mathrm{f}+\mathrm{d})-\sqrt{3}(2+3 \kappa)}<0
$$

For axisymmetric compression, the friction coefficient $f$ and the dilatancy coefficient $d$ are expressed in terms of the mobilized friction angle $\phi$ and dilatancy angle $\psi$

$$
\mathrm{f}=\frac{2 \sqrt{3} \sin \phi}{3-\sin \phi} \quad ; \quad \mathrm{d}=\frac{2 \sqrt{3} \sin \psi}{3-\sin \psi}
$$

In a simplified analysis, we take here the values of the friction and dilatancy coefficients at peak stress. For the Fontainebleau sandstone Poisson's ratio is $v=0.2$, the friction angle is $\phi=41.3^{\circ}$, and the dilatancy coefficient is fitted on the experimental data with a linear fit as a function of the confining pressure $\sigma_{3}$ (Fig.11)

$$
\mathrm{d}=\mathrm{d}_{1} \sigma_{3}+\mathrm{d}_{2}
$$

with $\mathrm{d}_{1}=-0.02$ and $\mathrm{d}_{2}=1.32$

When the shear band bifurcation condition (A5) is met two symmetric shear band directions exist given by

$$
\theta_{\mathrm{B}}= \pm \arctan (\sqrt[4]{(\mathrm{c} / \mathrm{a})})
$$

The critical hardening modulus $h_{B}$ is plotted on Fig. 27 versus the confining pressure. In flow theory of elastoplasticity, it is obtained that for axisymmetric compression conditions, shear banding occurs in the softening regime $(\mathrm{h}<0)$ [34]. The corresponding shear band orientation is presented on Fig. 28. 


\section{CAPTIONS TO TABLES AND FIGURES}

Table 1: Shear band orientation for drained and undrained tests

Table 2: Measured and estimated porosity

Table 3: Specific surface for Fontainebleau sandstone of various porosities (after [47])

Table 4: Measured and estimated permeability

Fig.1 Testing device

Fig. 2: Instrumentation of the sample inside the cell

Fig. 3: Microphotograph of an intact Fontainebleau sandstone.

Fig. 4: Drained tests: Deviatoric stress and volumetric strain versus axial stress

Fig. 5: Undrained tests: Deviatoric stress. volumetric strain and pore pressure versus axial stress

Fig. 6: Failure criterion for drained and undrained tests

Fig. 7: Lateral and radial surface of samples with a shear-band: (a) undrained test under 7MPa of confinement, (b) drained test under $28 \mathrm{MPa}$ of confinement

Fig. 8: Example of determination of the threshold of loss of homogeneous deformation (drained test at $28 \mathrm{MPa}$ of confining pressure)

Fig. 9: Onset of strain localisation: (a) drained tests, (b) undrained tests

Fig. 10: Onset of dilatancy and onset of strain localisation

Fig. 11: Dilatancy angle versus effective confining pressure

Fig. 12: Shear band orientation versus the minor principal stress for drained and undrained tests

Fig. 13: Microphotographs of a shear band formed in undrained test under $7 \mathrm{MPa}$ of confinement: General view and details

Fig. 14: Microphotographs of a shear band formed in a drained test under 50MPa of confinement: General view and detail

Fig. 15: Example of binary image (b) obtained from the original grey level image (a)

Fig. 16: Microphotographs of a shear band formed under $14 \mathrm{MPa}$ of total confinement: (a) drained tests; (b) undrained test

Fig. 17: Microphotographs of a shear band formed in drained tests: (a) $28 \mathrm{MPa}$; (b) $40 \mathrm{MPa}$; (c) $50 \mathrm{MPa}$

Fig. 18: Microphotographs of a shear band formed in undrained tests: (a) $28 \mathrm{MPa}$; (b) $40 \mathrm{MPa}$; (c) $50 \mathrm{MPa}$

Fig. 19: Channels formed in undrained tests: (a) $28 \mathrm{MPa}$; (b) $40 \mathrm{MPa}$; (c) $50 \mathrm{MPa}$

Fig. 20: Example of a image on which the porosity is evaluated

Fig. 21: Porosity evolution in the direction perpendicular to the major (in absolute value) principal stress axis: (a) drained tests; (b) undrained tests

Fig. 22: Average porosity evaluated inside the shear band for drained and undrained

Fig. 23: Evaluation of the formation factor

Fig. 24: Permeability evaluation on intact samples and comparison with Bourbier and Zinsner [49] power law

Fig. 25: Evaluation of the permeability inside the shear bands for drained tests

Fig. 26: Evaluation of the permeability inside the shear bands for undrained tests

Fig. 27: Critical hardening modulus at shear banding

Fig. 28: Computed shear band orientation 


\begin{tabular}{|c|c|c|}
\hline $\begin{array}{c}\text { Total confining } \\
\text { pressure } \\
\text { (MPa) }\end{array}$ & $\begin{array}{c}\text { Shear band } \\
\text { orientation } \\
\text { Drained tests } \\
\left({ }^{\circ}\right)\end{array}$ & $\begin{array}{c}\text { Shear band } \\
\text { orientation } \\
\text { Undrained tests } \\
\left({ }^{\circ}\right)\end{array}$ \\
\hline 7 & 69.7 & 70 \\
14 & 63.4 & 69 \\
28 & 61.9 & $66-68$ \\
40 & $57-60$ & $63.5-66.5$ \\
50 & 54 & $60-62$ \\
\hline
\end{tabular}

Table 1: Shear band orientation for drained and undrained tests 


\begin{tabular}{|c|c|c|c|c|}
\hline \multirow{2}{*}{$\begin{array}{c}\text { Test } \\
\text { reference }\end{array}$} & $\begin{array}{c}\text { Experimental measurements of } \\
\text { porosity (\%) }\end{array}$ & \multicolumn{2}{|c|}{ Image analysis } \\
\cline { 2 - 5 } & $\begin{array}{c}\text { Water } \\
\text { imbibation }\end{array}$ & $\begin{array}{c}\text { Mercury } \\
\text { porosimetry }\end{array}$ & $\begin{array}{c}\text { Evaluated } \\
\text { porosity } \\
(\%)\end{array}$ & $\begin{array}{c}\text { Evaluated } \\
\text { specific surface } \\
\left(\mathbf{m m}^{-1}\right)\end{array}$ \\
\hline $877 \mathrm{E}$ & 7.25 & 6.32 & 7.08 & 15.55 \\
$878 \mathrm{~B}$ & 11.24 & 10.62 & 9.6 & 15.06 \\
$878 \mathrm{~A}$ & 14.11 & 13.25 & 14.05 & 16.08 \\
$878 \mathrm{E}$ & 17.12 & 19.74 & 17.63 & 19.29 \\
$878 \mathrm{D}$ & 18.19 & 17.18 & 21.13 & 22.03 \\
\hline
\end{tabular}

Table 2: Measured and estimated porosity 


\begin{tabular}{|c|c|c|}
\hline Sample & $\begin{array}{c}\text { Porosity } \\
(\mathbf{\%})\end{array}$ & $\begin{array}{c}\text { Specific surface } \\
\left(\mathbf{m m}^{-\mathbf{1}}\right)\end{array}$ \\
\hline F1 & 4.6 & $9.36 \pm 2.76$ \\
F4 & 10.7 & $20.32 \pm 4.76$ \\
F7 & 15.9 & $22.44 \pm 3.64$ \\
F8 & 20.5 & $19.76 \pm 2.28$ \\
\hline
\end{tabular}

Table 3: Specific surface for Fontainebleau sandstone of various porosities (after [47]) 


\begin{tabular}{|c|c|c|c|c|c|}
\hline $\begin{array}{c}\text { Test } \\
\text { reference }\end{array}$ & $\begin{array}{c}\text { Evaluated } \\
\text { porosity } \\
\mathbf{( \% )}\end{array}$ & $\begin{array}{c}\text { Evaluated } \\
\text { specific surface } \\
\left(\mathbf{m m}^{-\mathbf{1}}\right)\end{array}$ & $\begin{array}{c}\text { Estimated } \\
\text { permeability } \\
\text { (mDarcy) } \\
\text { Walsh and } \\
\text { Brace model } \\
(\mathbf{b}=\mathbf{2})\end{array}$ & $\begin{array}{c}\text { Estimated } \\
\text { permeability } \\
\text { (mDarcy) } \\
\text { Walsh and } \\
\text { Brace model } \\
(\mathbf{b}=\mathbf{3})\end{array}$ & $\begin{array}{c}\text { Measured } \\
\text { permeability } \\
\text { (mDarcy) } \\
(\mathbf{e q .} \text { 10, after } \\
\text { [49]) }\end{array}$ \\
\hline $877 \mathrm{E}$ & 7.08 & 15.55 & 128.5 & 85.6 & 118.6 \\
$878 \mathrm{~B}$ & 9.6 & 15.06 & 389.1 & 259.4 & 300.2 \\
$878 \mathrm{~A}$ & 14.05 & 16.08 & 1258.9 & 839.3 & 959.1 \\
$878 \mathrm{E}$ & 17.63 & 19.29 & 1902.7 & 1268.5 & 1916.5 \\
$878 \mathrm{D}$ & 21.13 & 22.03 & 2713.3 & 1808.9 & 3329.5 \\
\hline
\end{tabular}

Table 4: Measured and estimated permeability 

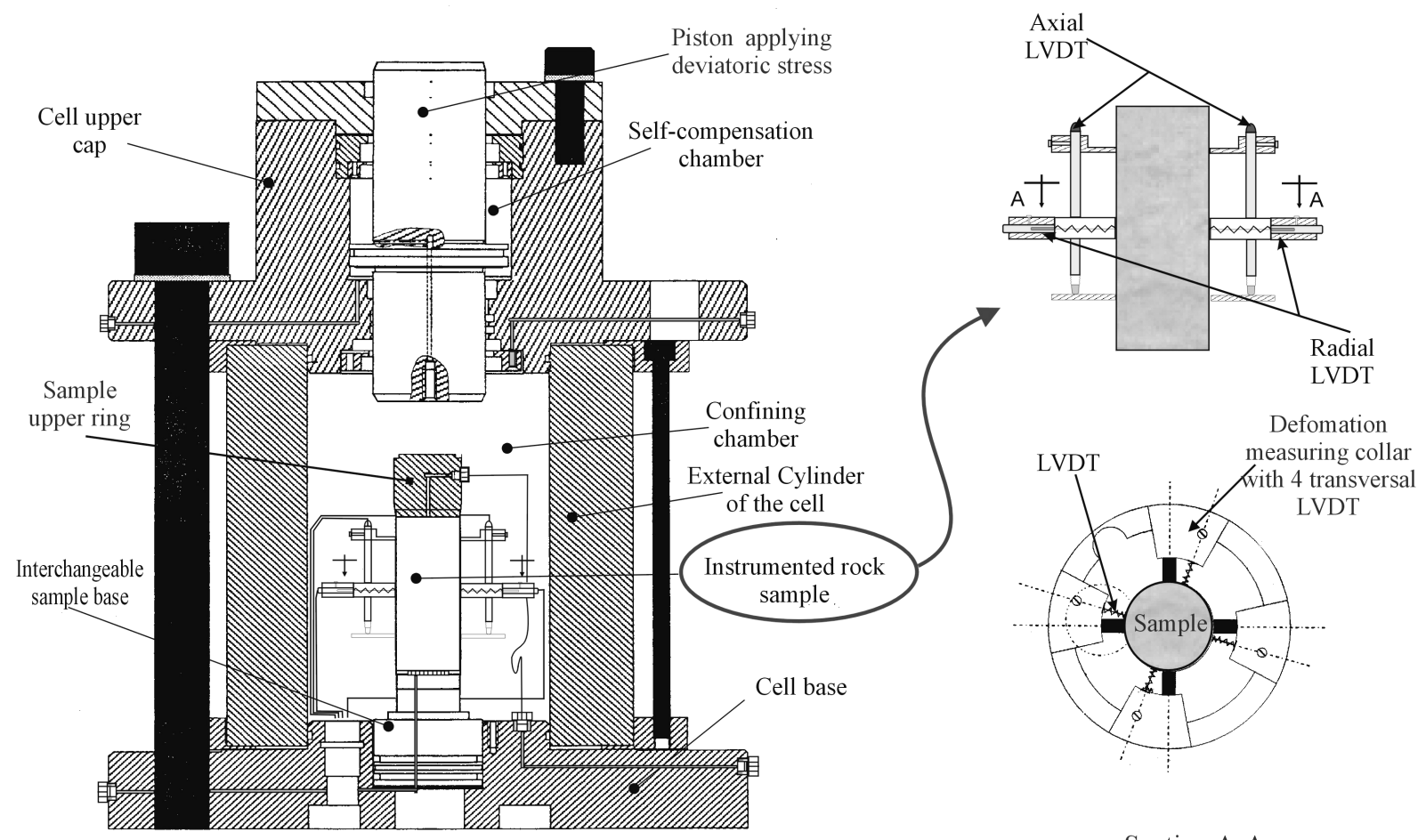

Section A-A

Fig.1 Testing device 


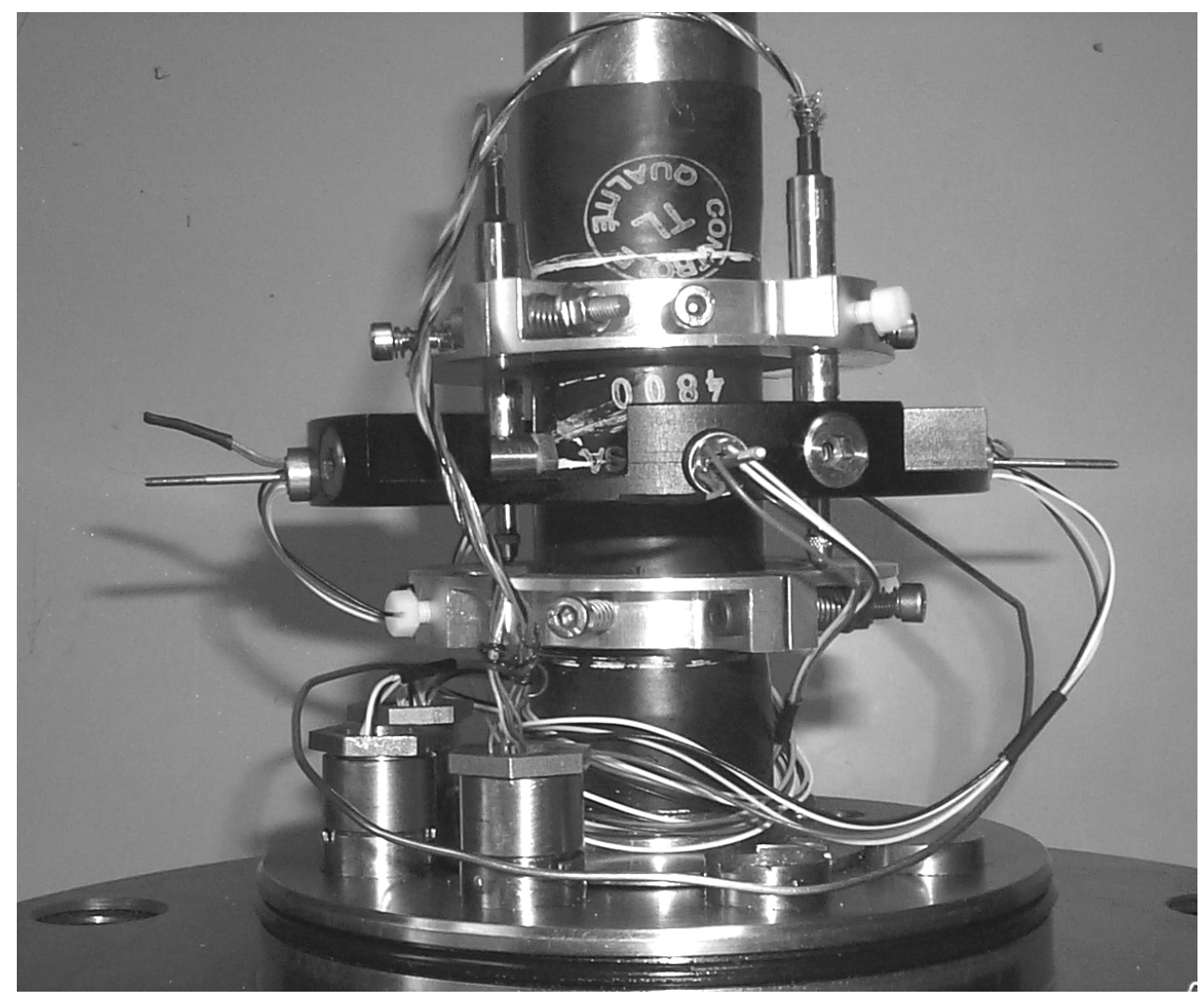

Fig. 2: Instrumentation of the sample inside the cell 


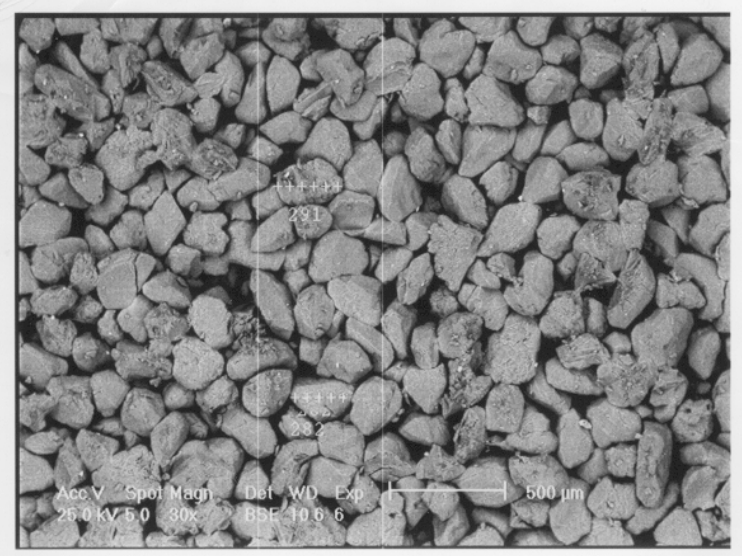

Fig. 3: Microphotograph of an intact Fontainebleau sandstone. 

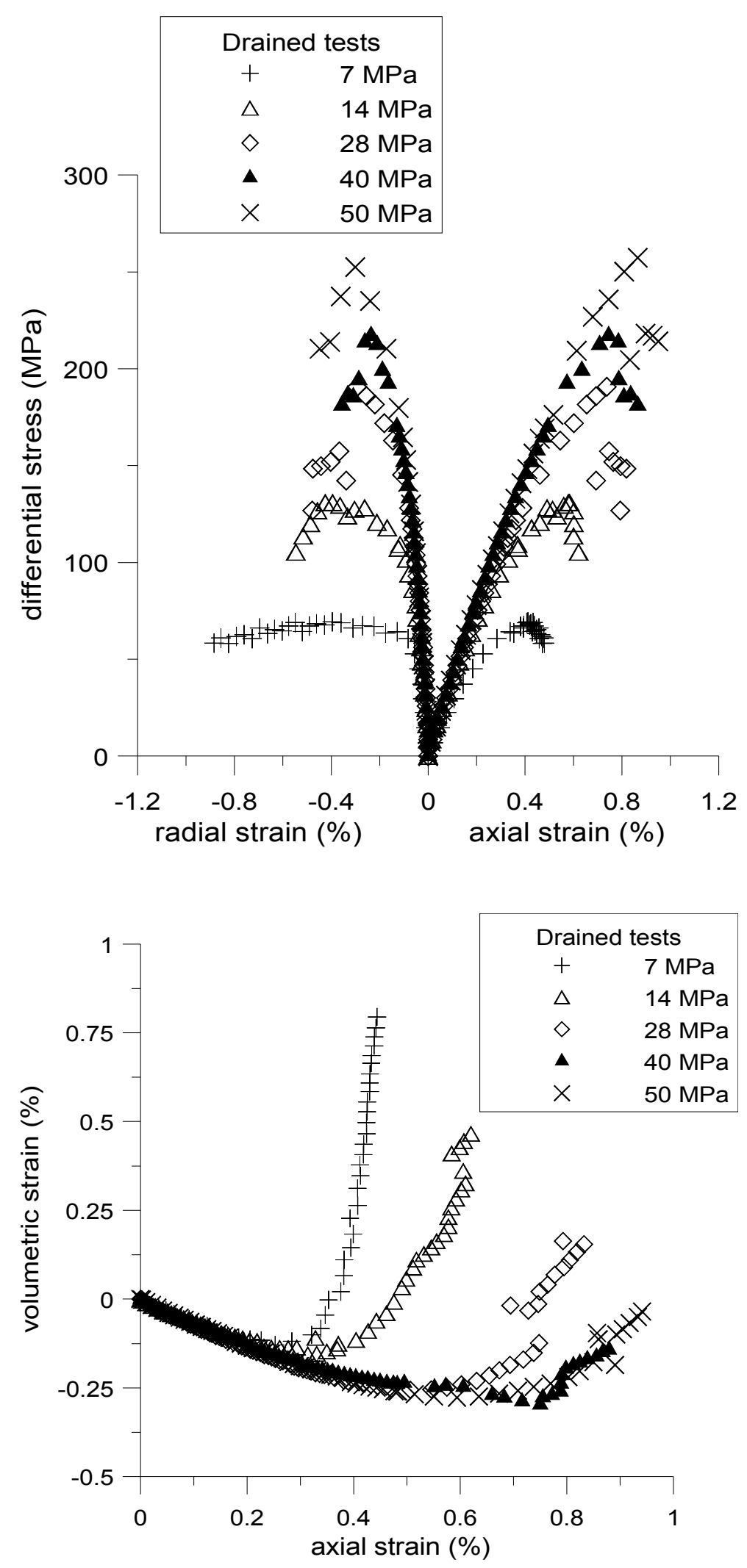

Fig. 4: Drained tests: Deviatoric stress and volumetric strain versus axial stress 

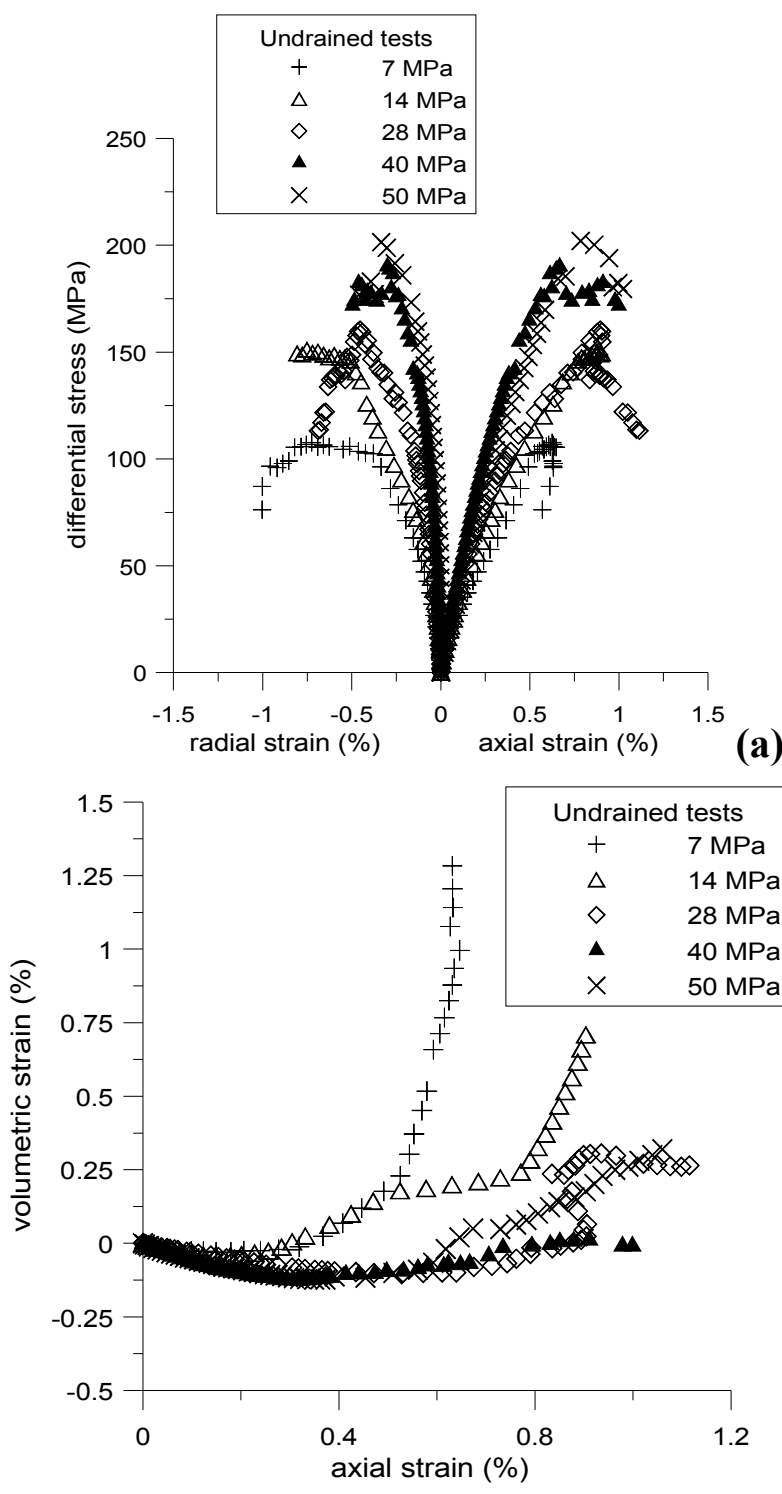

(b)

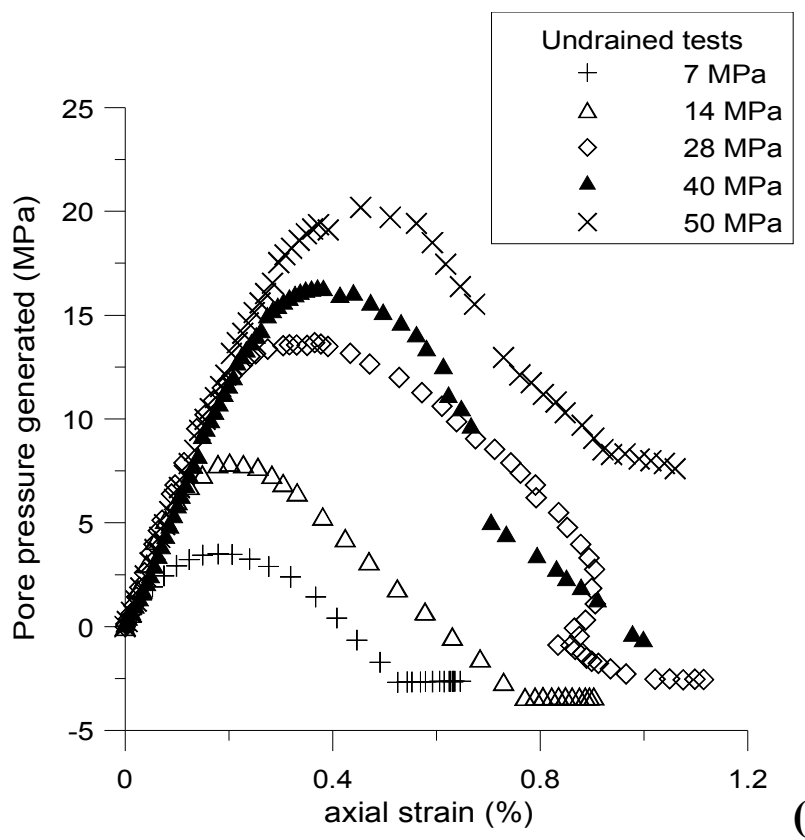

(c)

Fig. 5: Undrained tests: Deviatoric stress. volumetric strain and pore pressure versus axial stress 


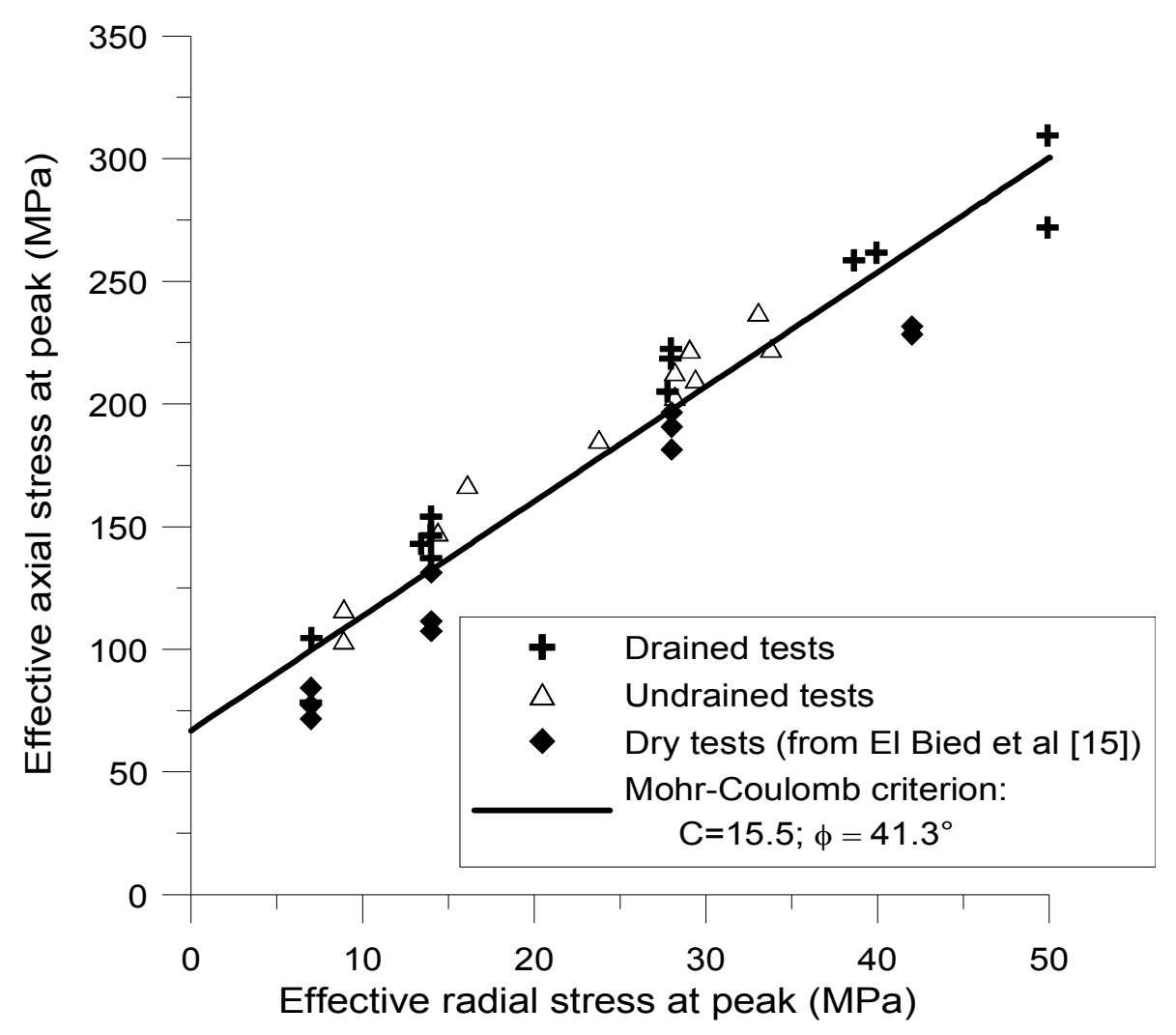

Fig. 6: Failure criterion for drained and undrained tests 


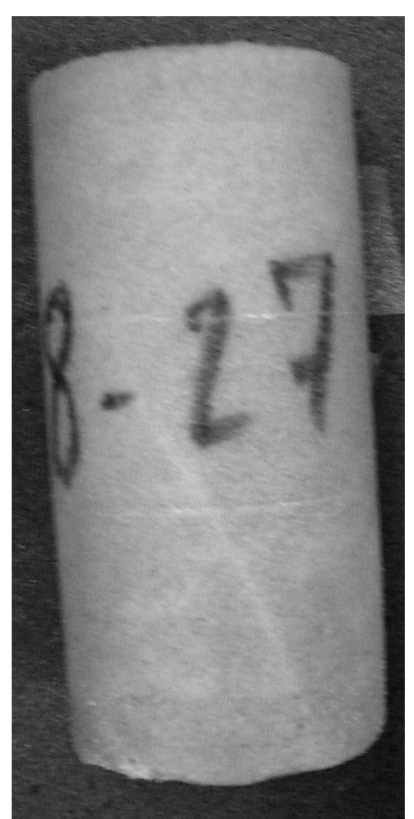

(a)

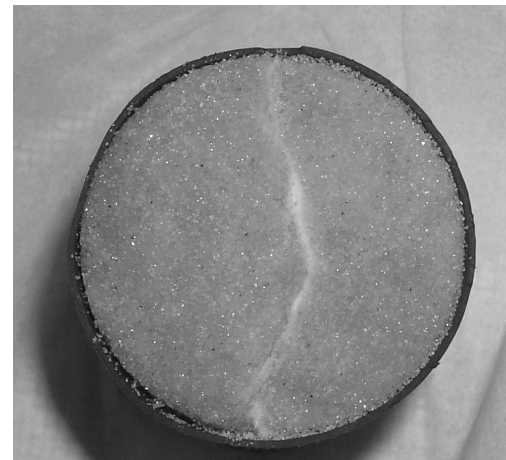

(b)

Fig. 7: Lateral and radial surface of samples with a shear-band: (a) undrained test under 7MPa of confinement, (b) drained test under 28 MPa of confinement 

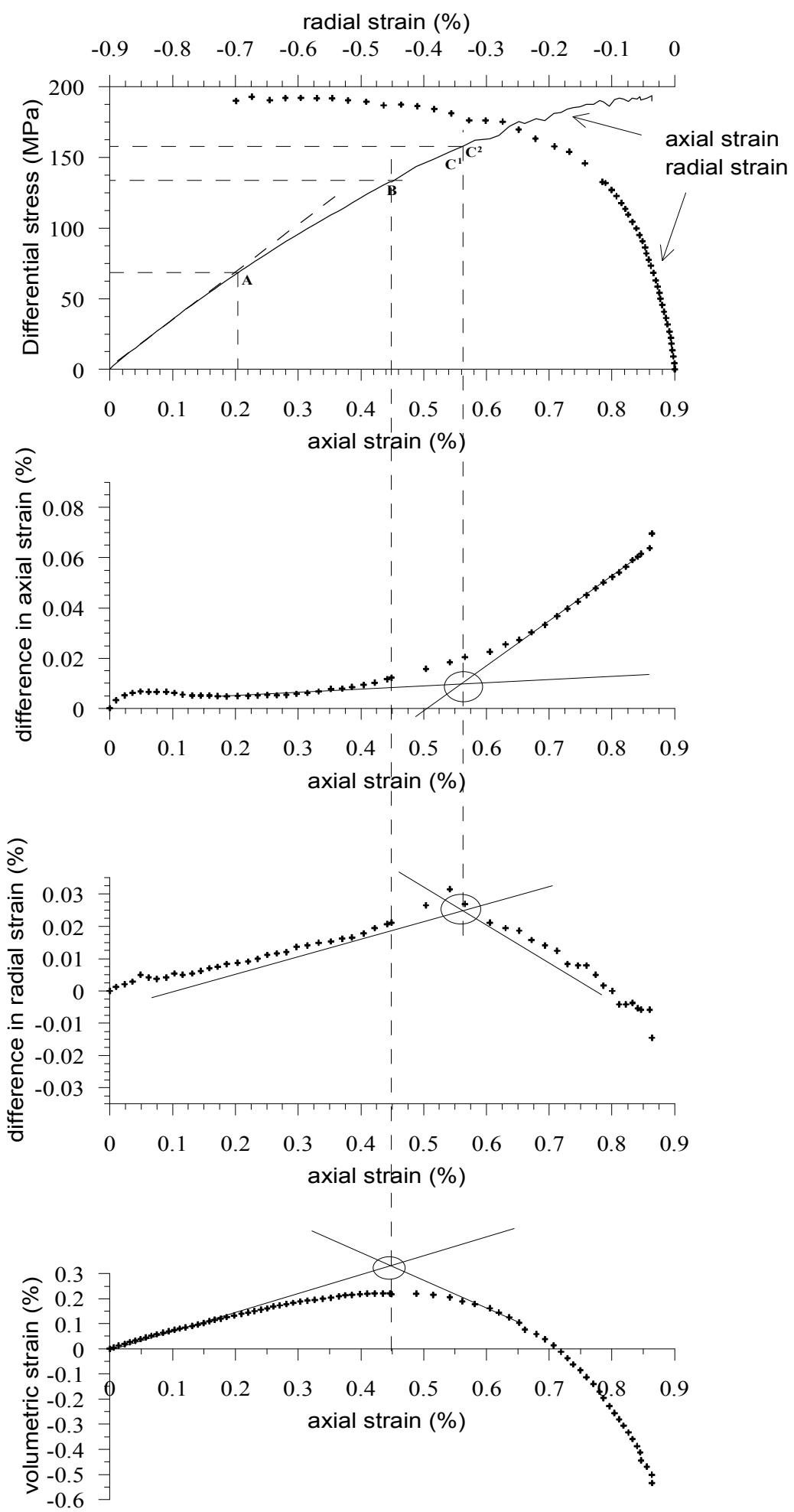

Fig. 8: Example of determination of the threshold of loss of homogeneous deformation (drained test at 28 MPa of confining pressure) 


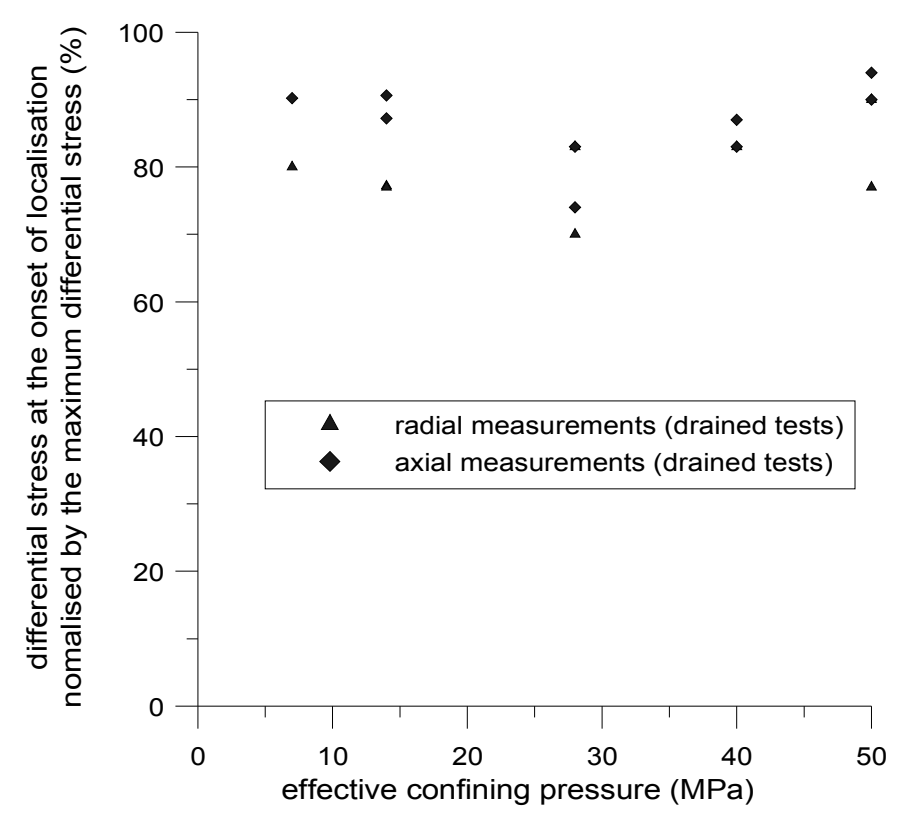

(a)

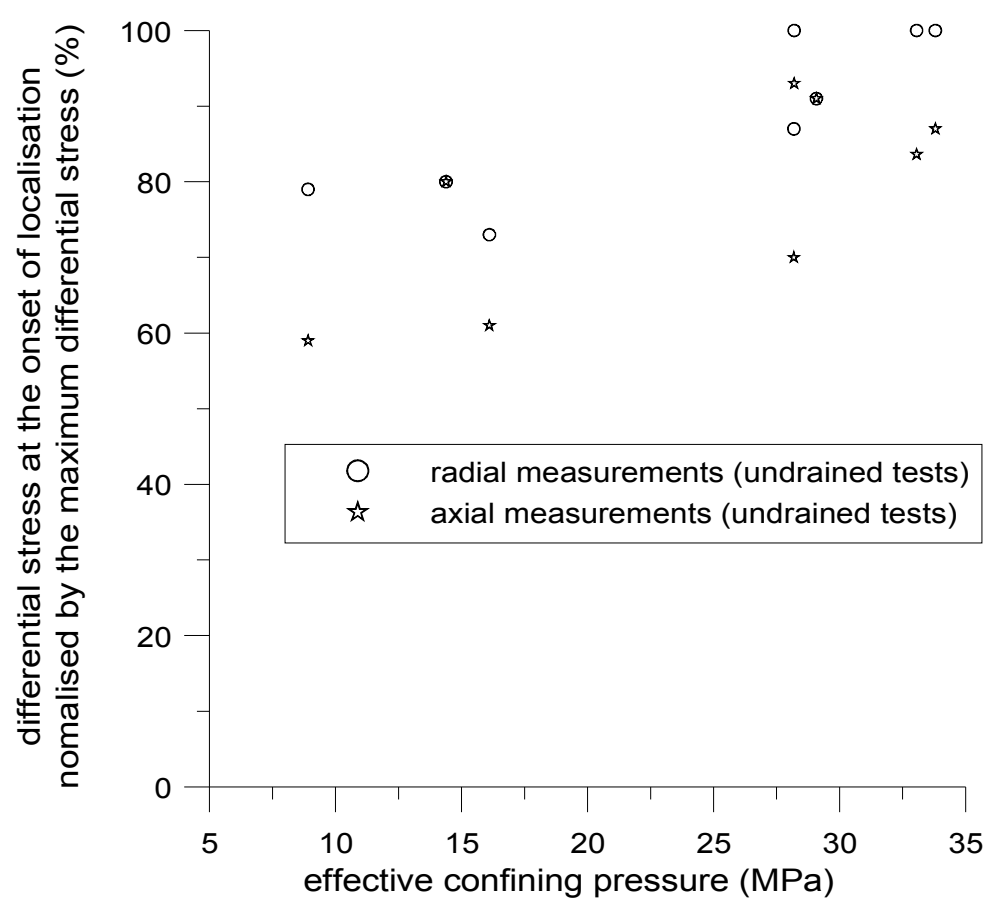

(b)

Fig. 9: Onset of strain localisation (a) drained tests, (b) undrained tests 


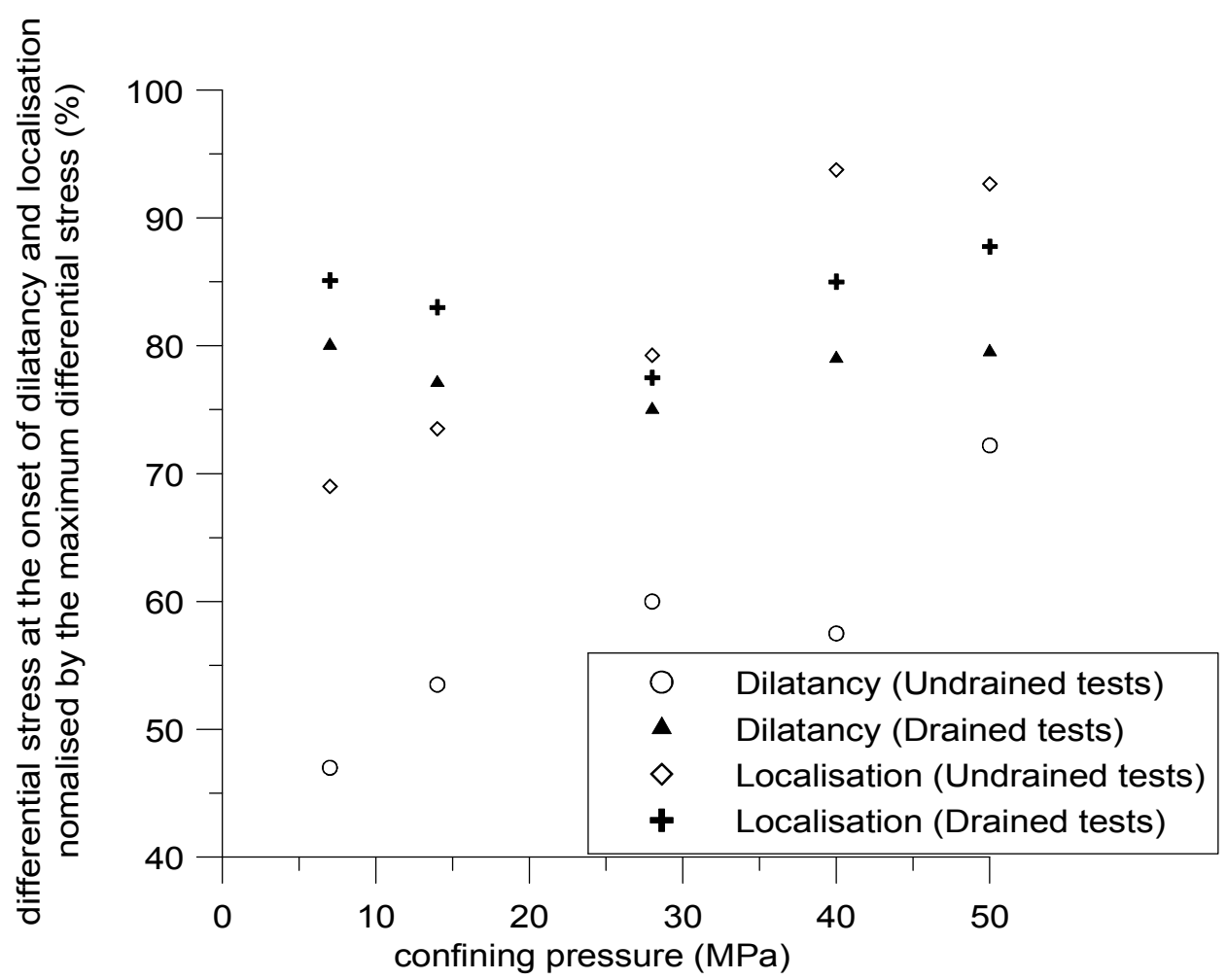

Fig. 10: onset of dilatancy and onset of strain localisation 


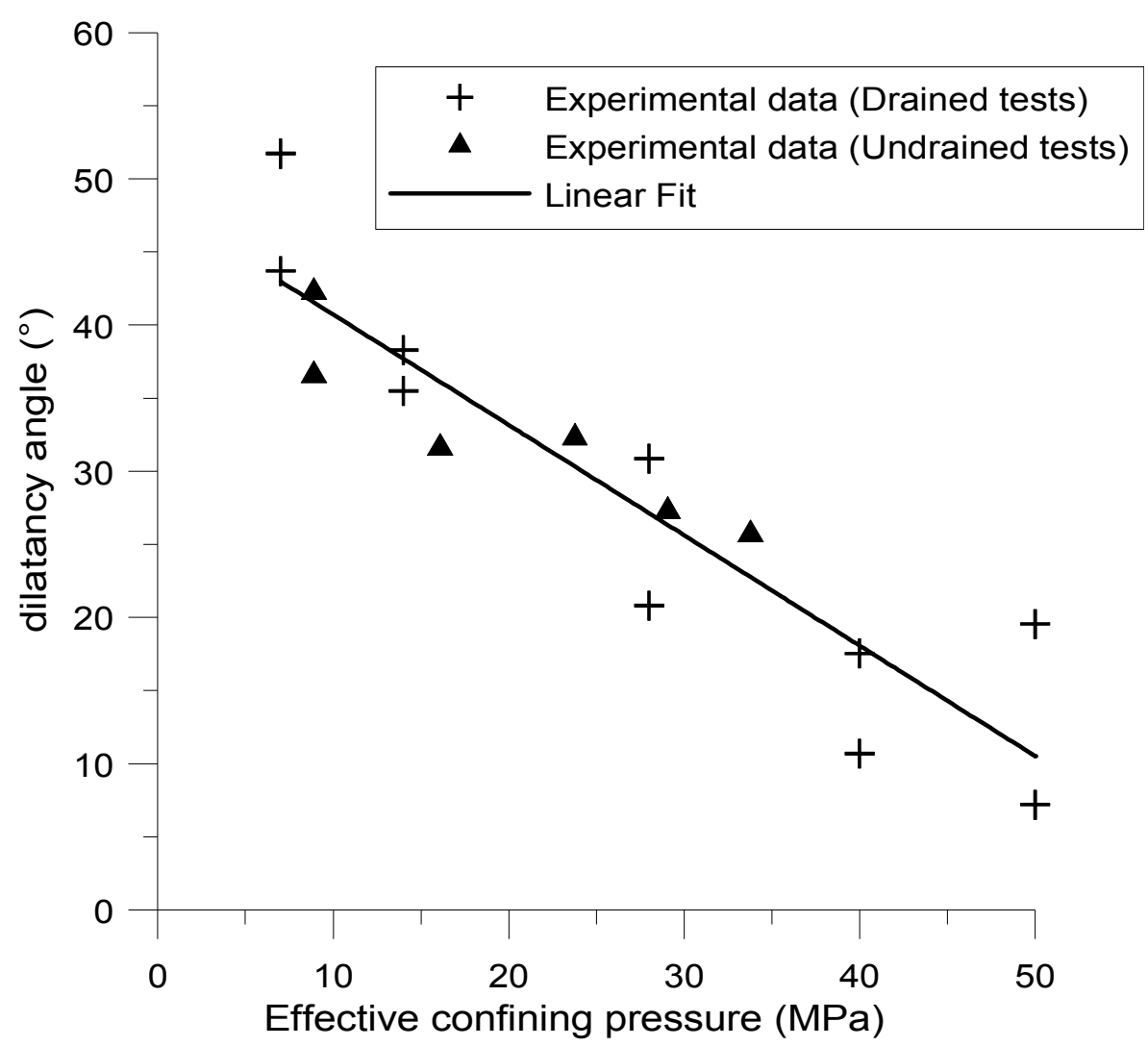

Fig. 11: Dilatancy angle versus effective confining pressure 


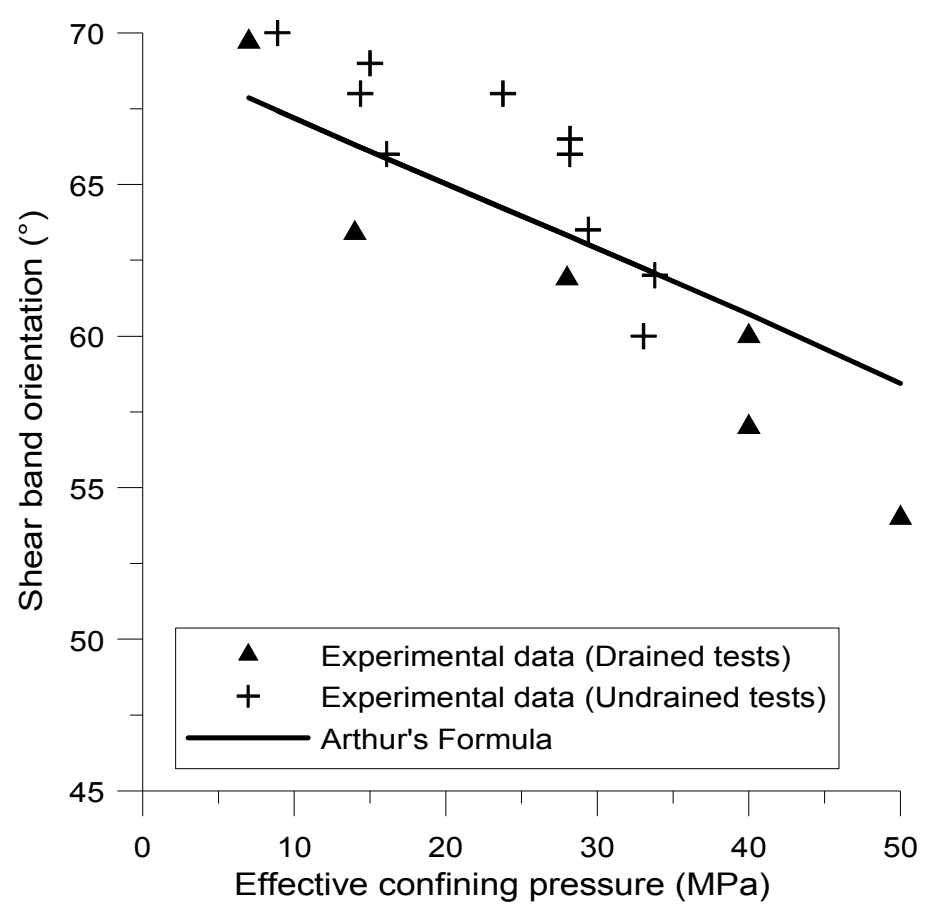

(a)

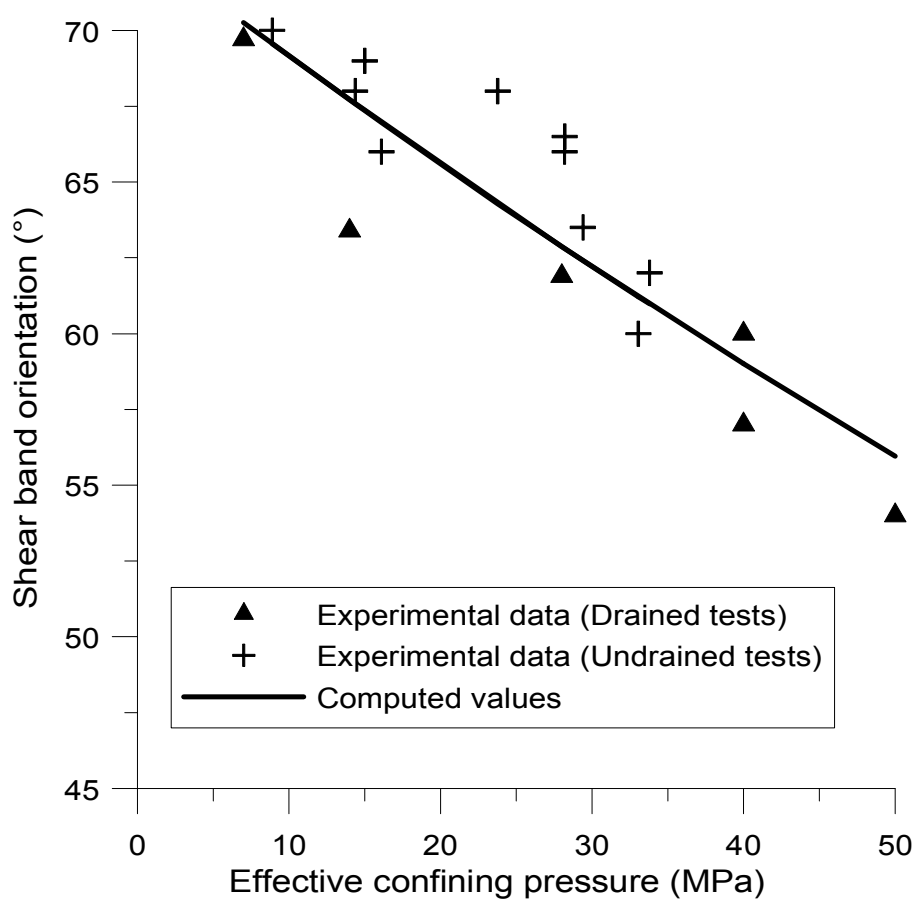

(b)

Fig. 12: Shear band orientation versus the minor principal stress for drained and undrained tests (a) Arthur formula, (b) complete strain localisation analysis 


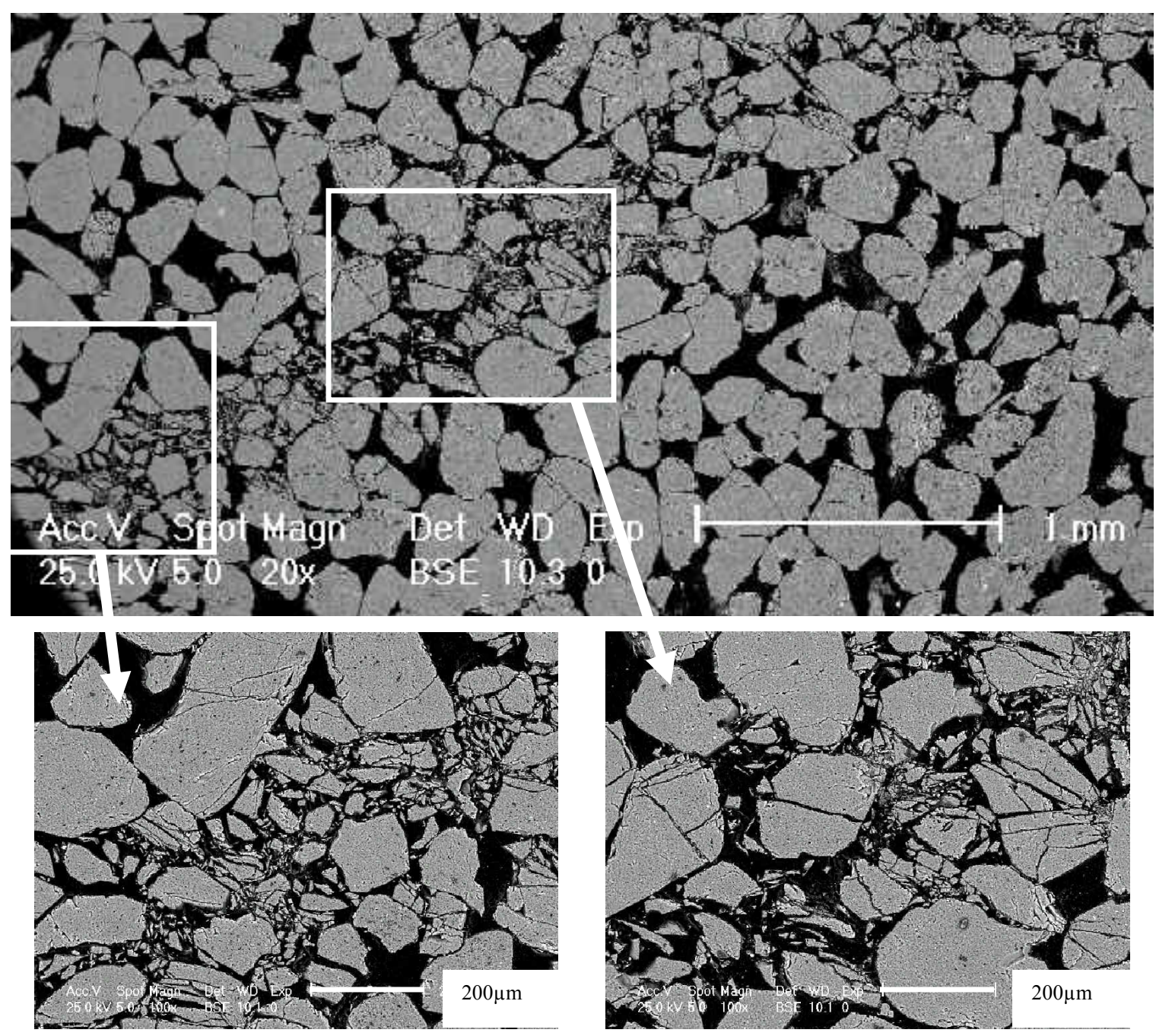

Fig. 13: Microphotographs of a shear band formed in undrained test under 7MPa of confinement: General view and details 

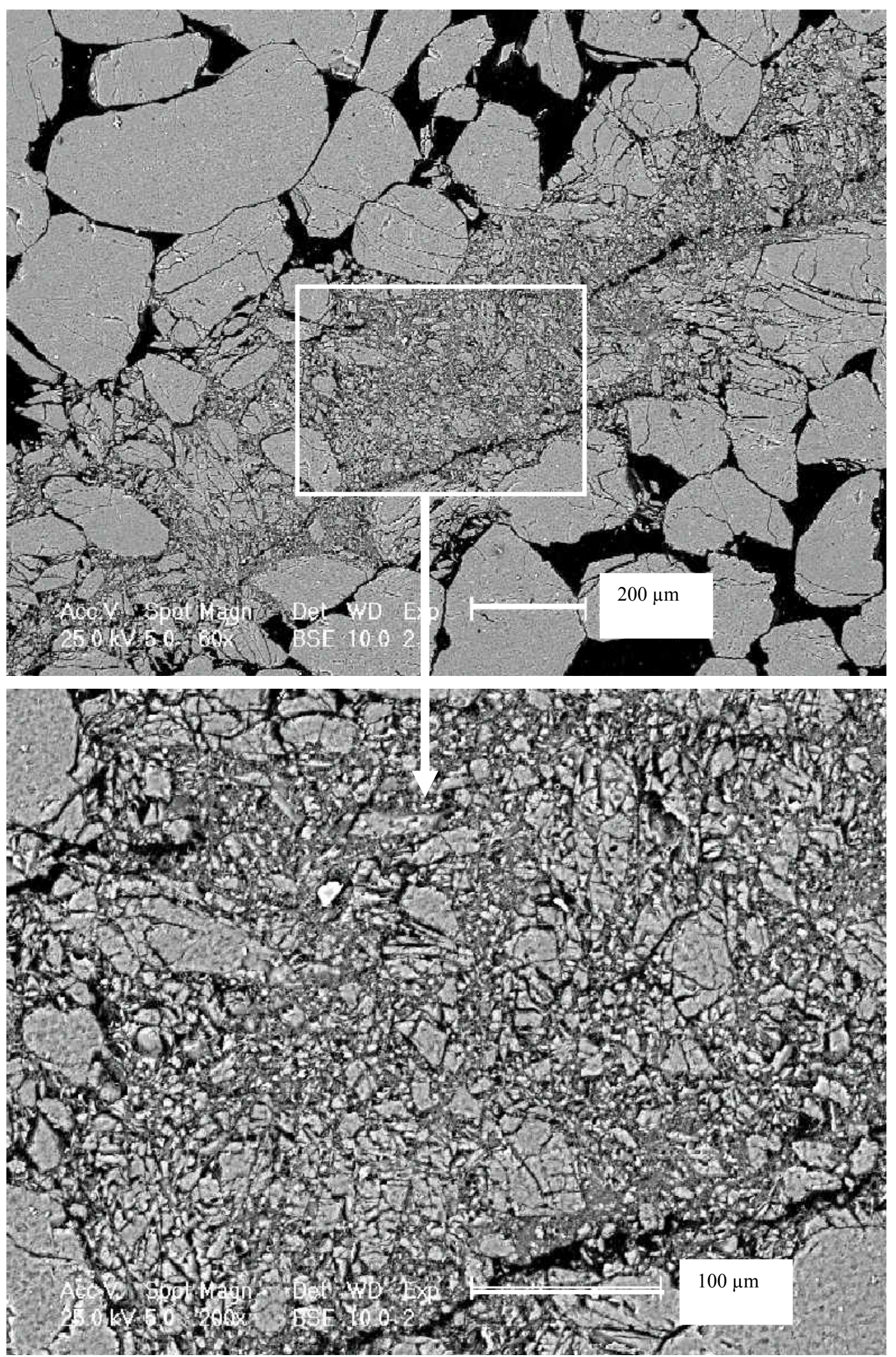

Fig. 14: Microphotographs of a shear band formed in a drained test under 50MPa of confinement: General view and detail 

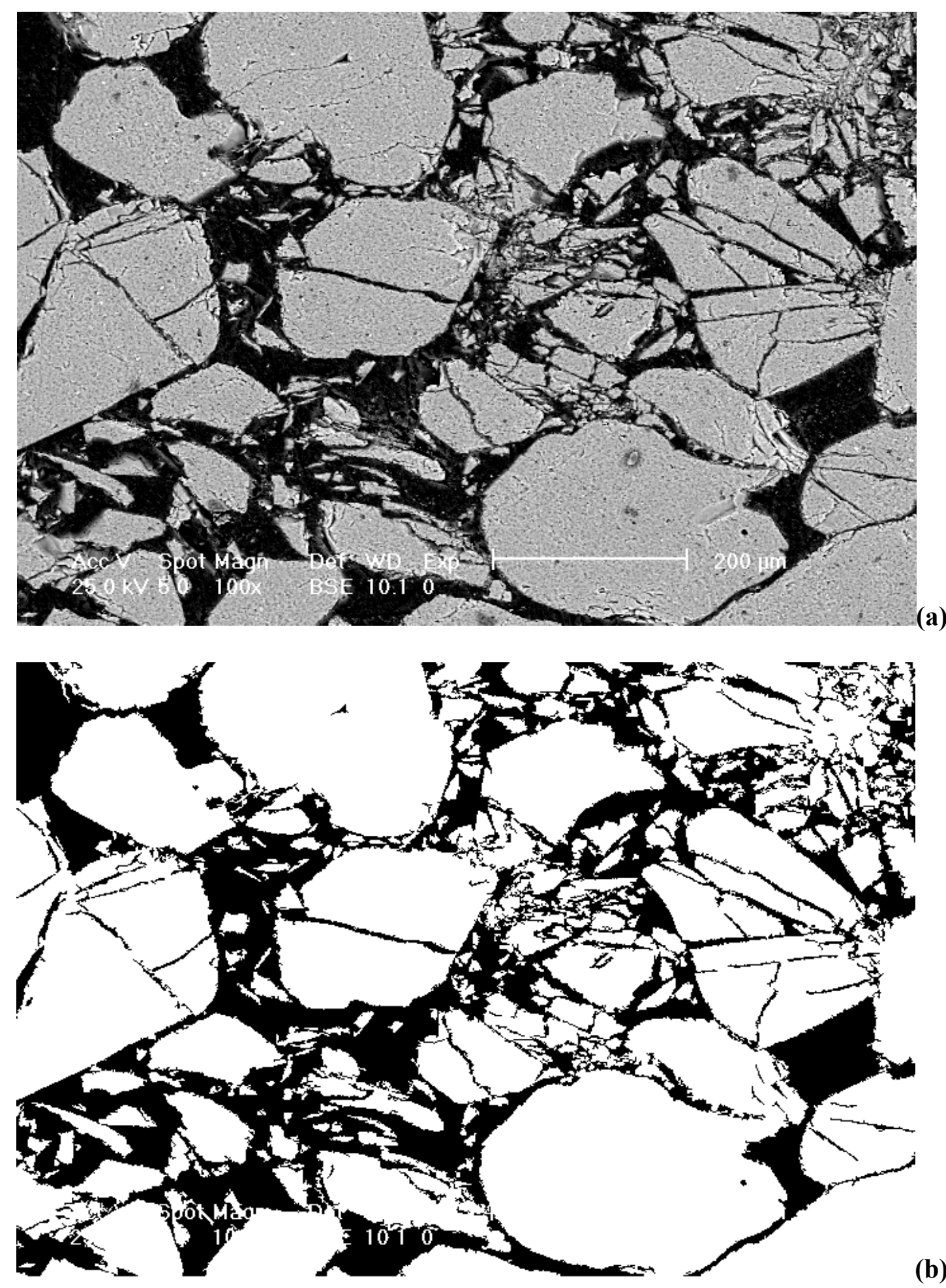

Fig. 15: Example of binary image (b) obtained from the original grey level image (a) 


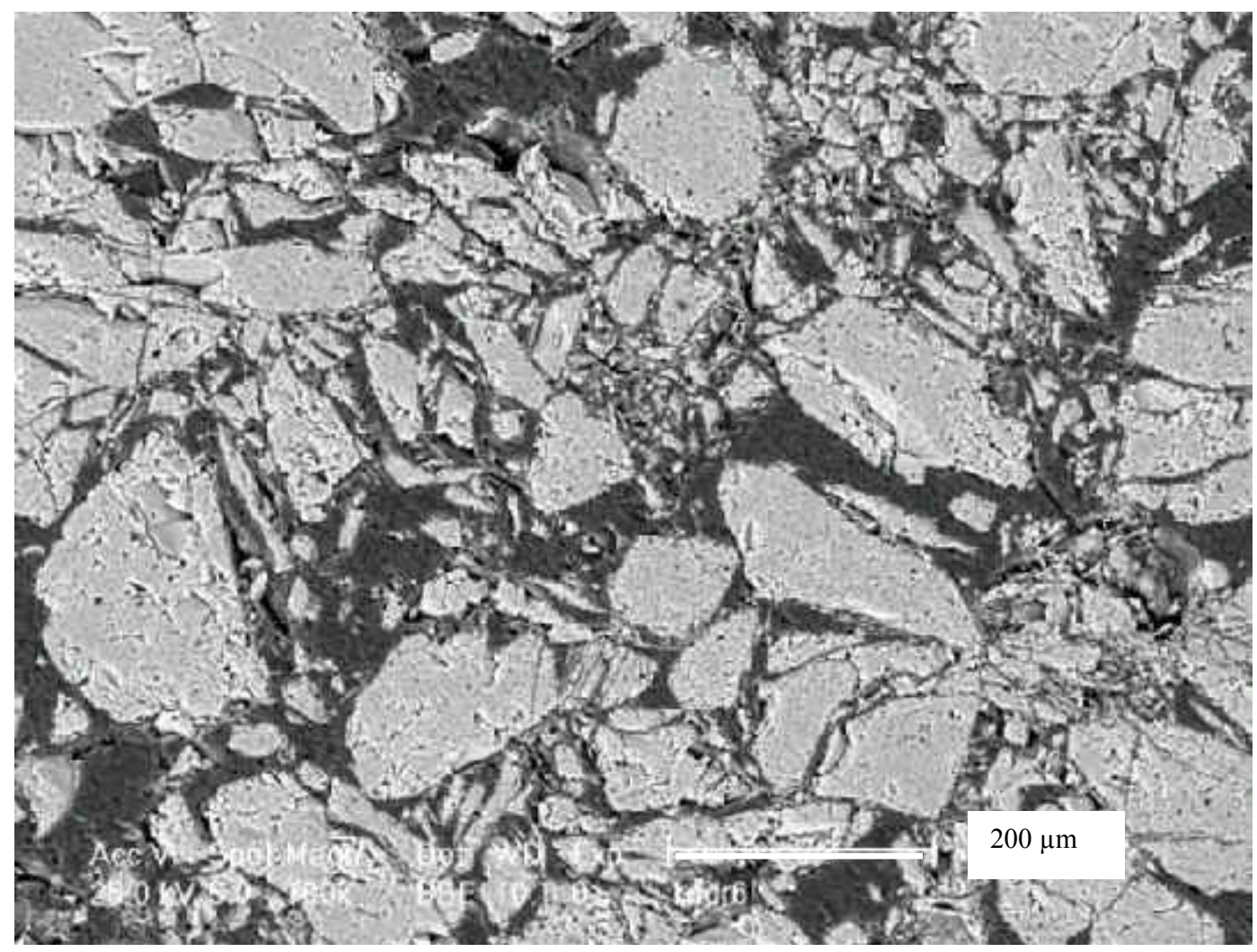

(a)

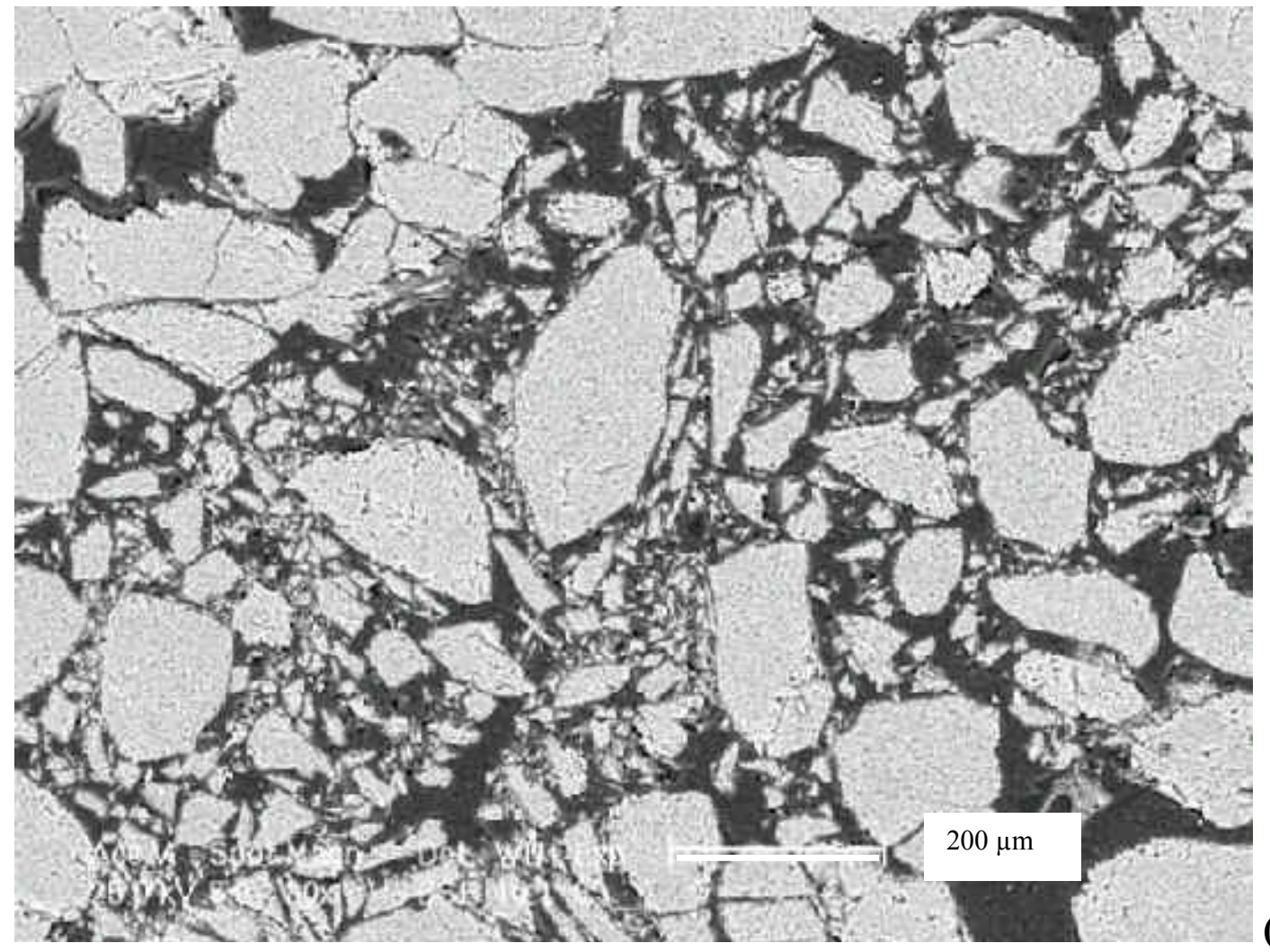

(b)

Fig. 16: Microphotographs of a shear band formed under 14 MPa of total confinement: (a) drained tests; (b) undrained test 


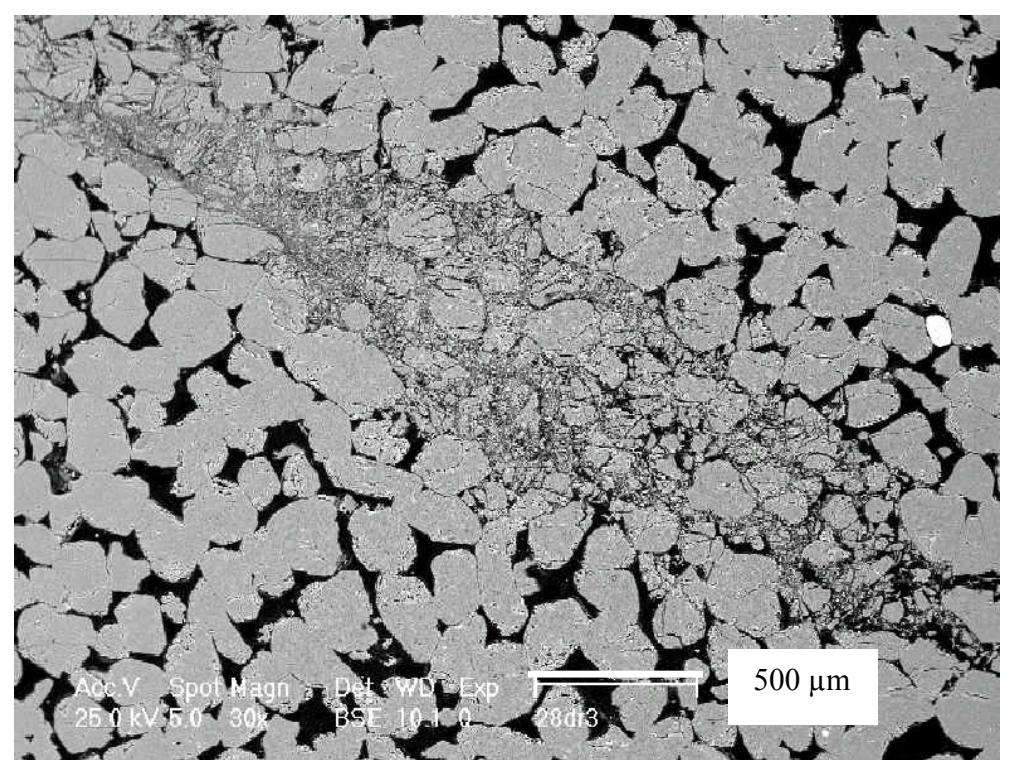

(a)
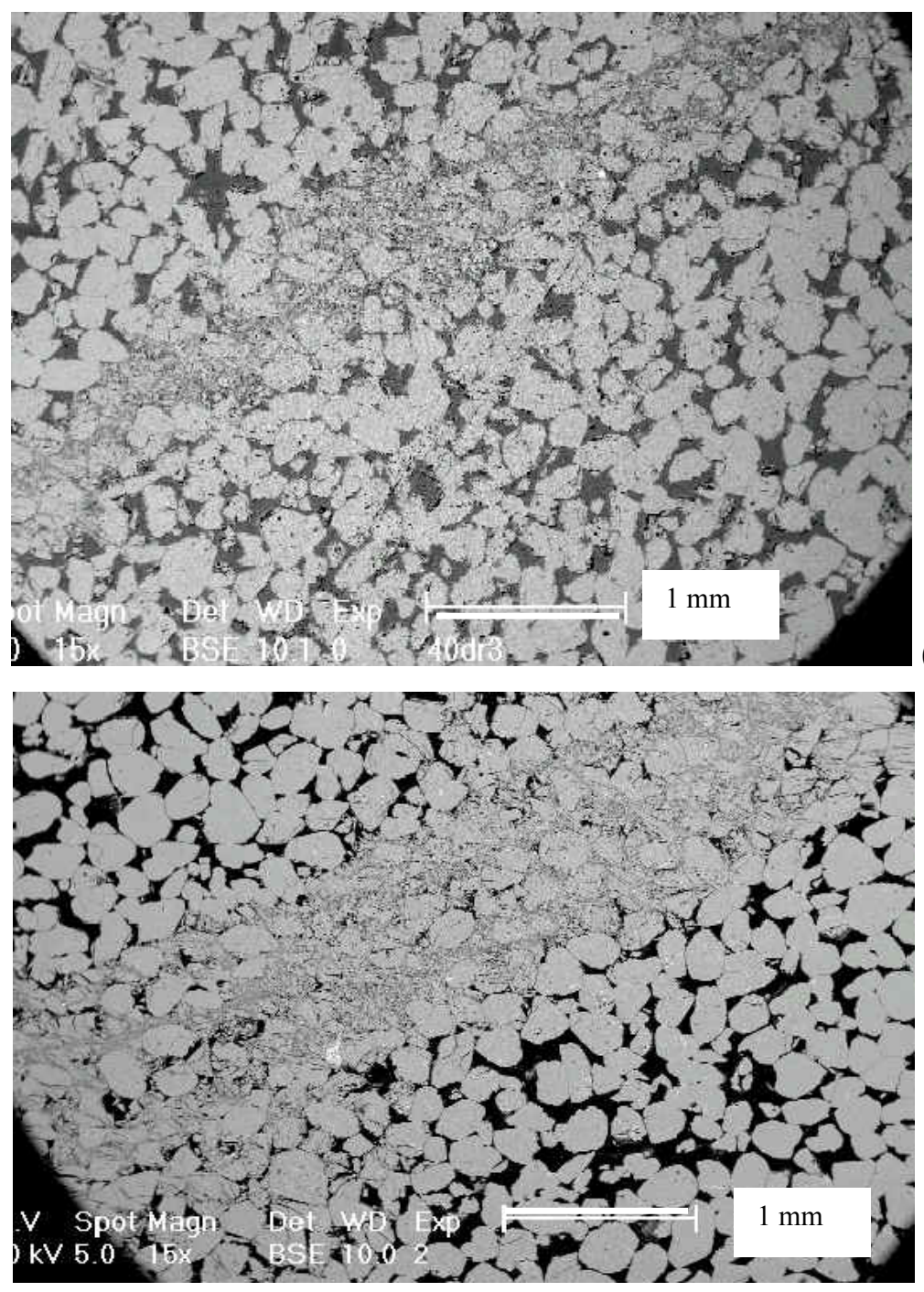

Fig. 17: Microphotographs of a shear band formed in drained tests:

(a) $28 \mathrm{MPa}$; (b) $40 \mathrm{MPa}$; (c) $50 \mathrm{MPa}$ 

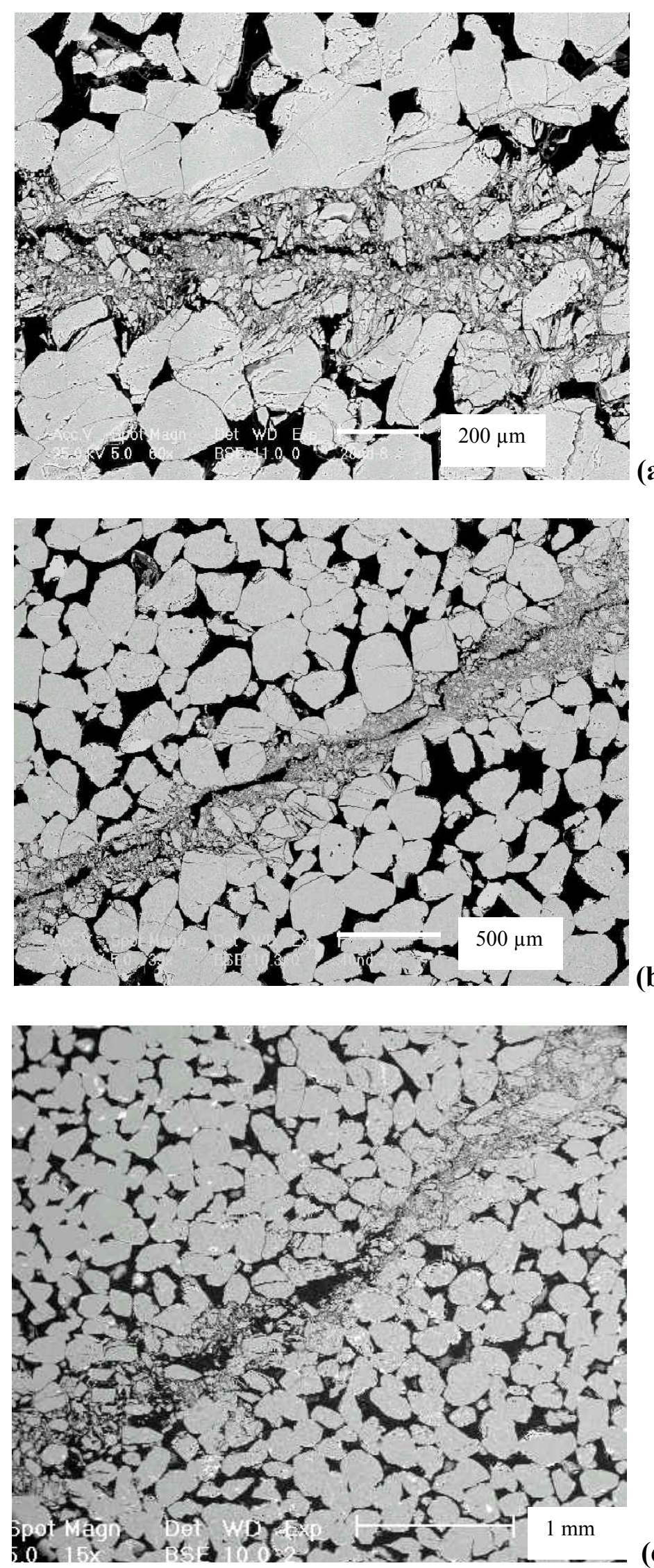

Fig. 18: Microphotographs of a shear band formed in undrained tests:

(a) $28 \mathrm{MPa}$; (b) $40 \mathrm{MPa}$; (c) $50 \mathrm{MPa}$ 


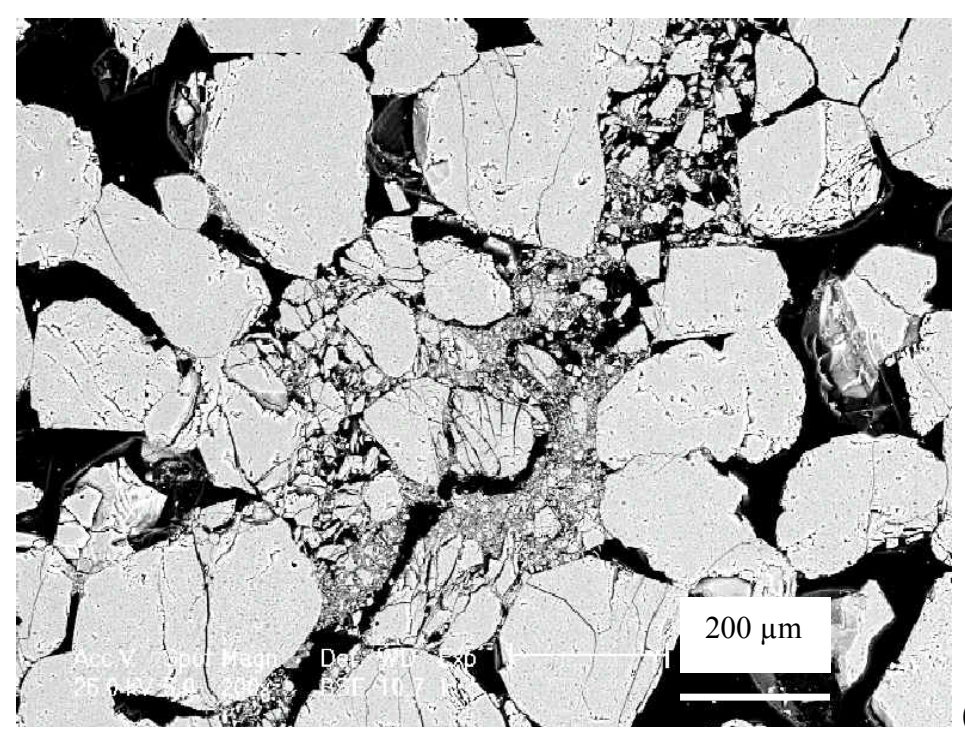

(a)

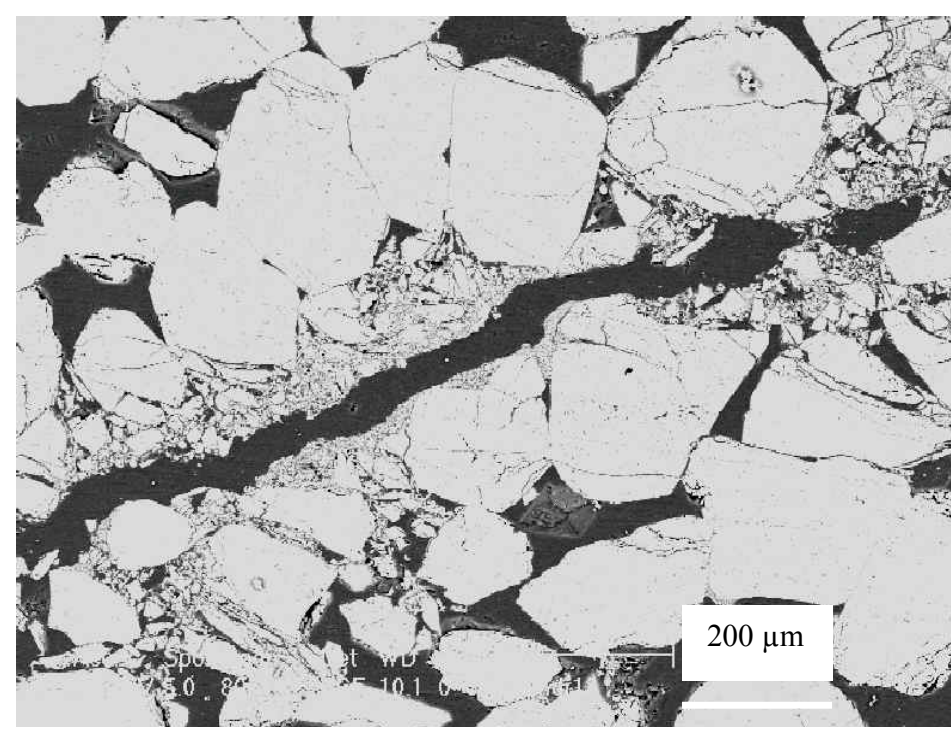

(b)

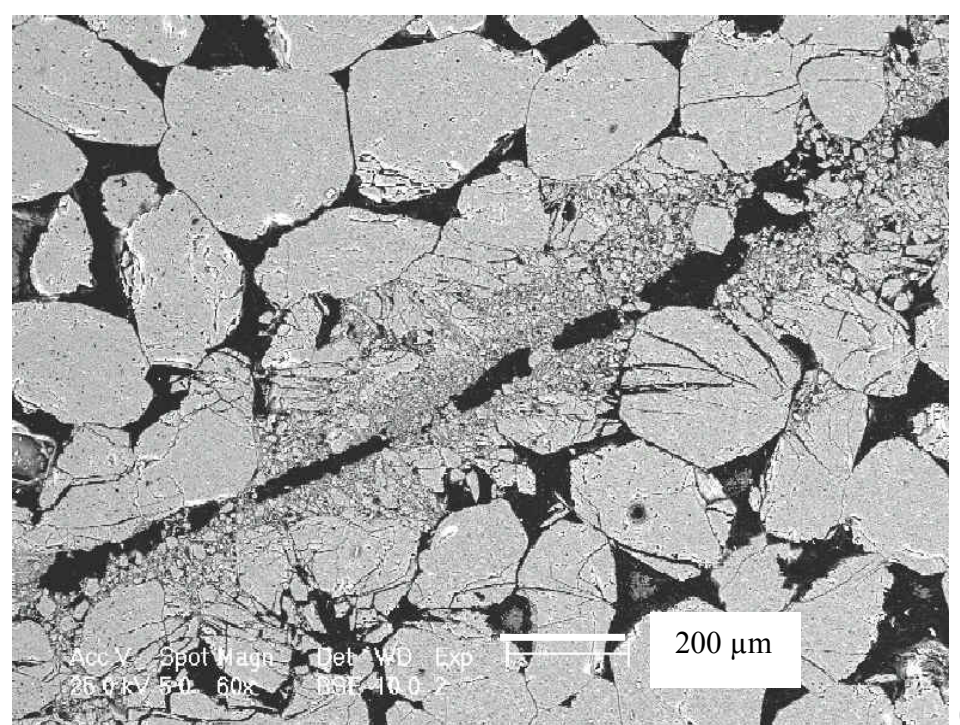

(c)

Fig. 19: Channels formed in undrained tests:

(a) $28 \mathrm{MPa}$; (b) $40 \mathrm{MPa}$; (c) $50 \mathrm{MPa}$ 


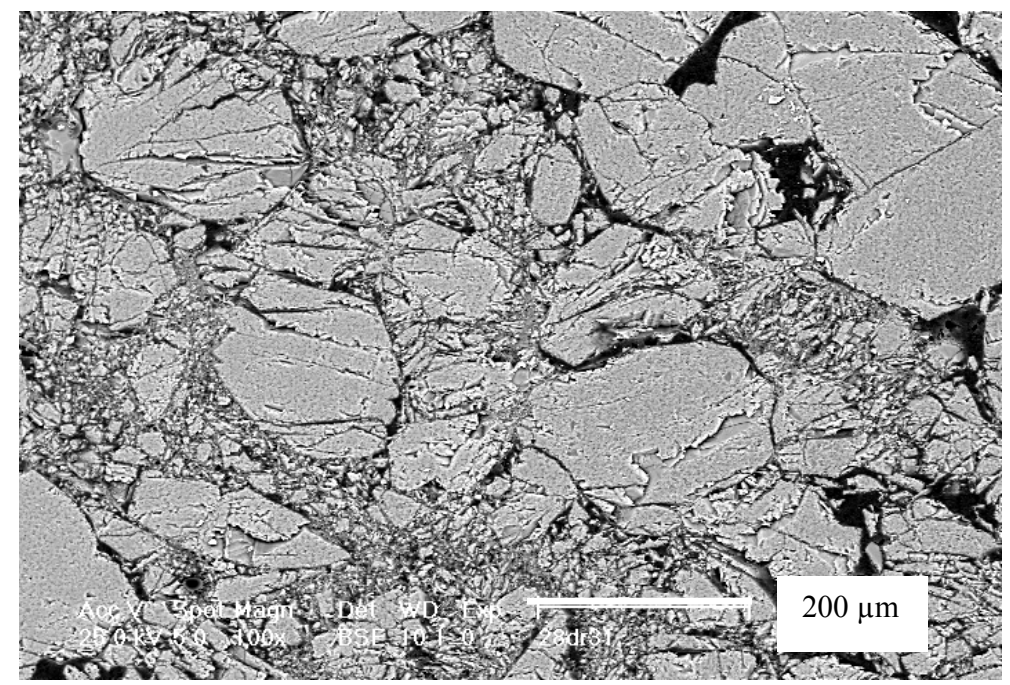

Fig. 20: Example of an image on which the porosity is evaluated 


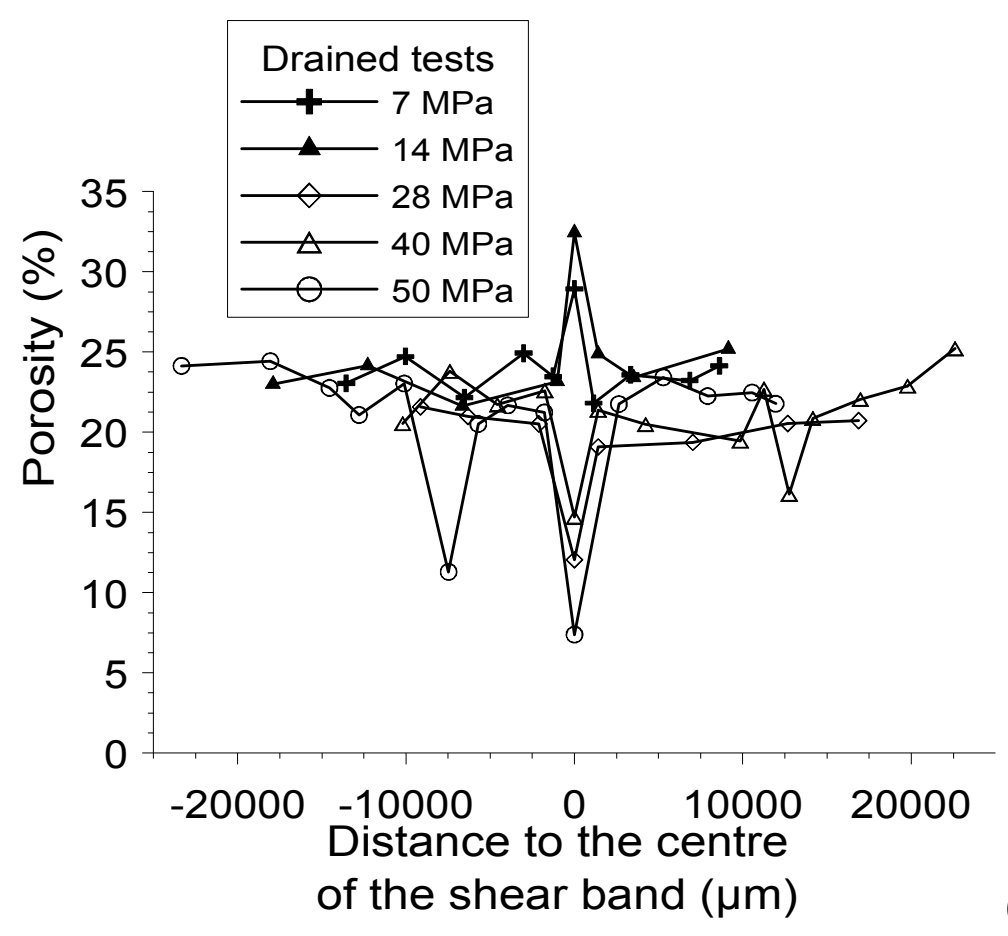

(a)

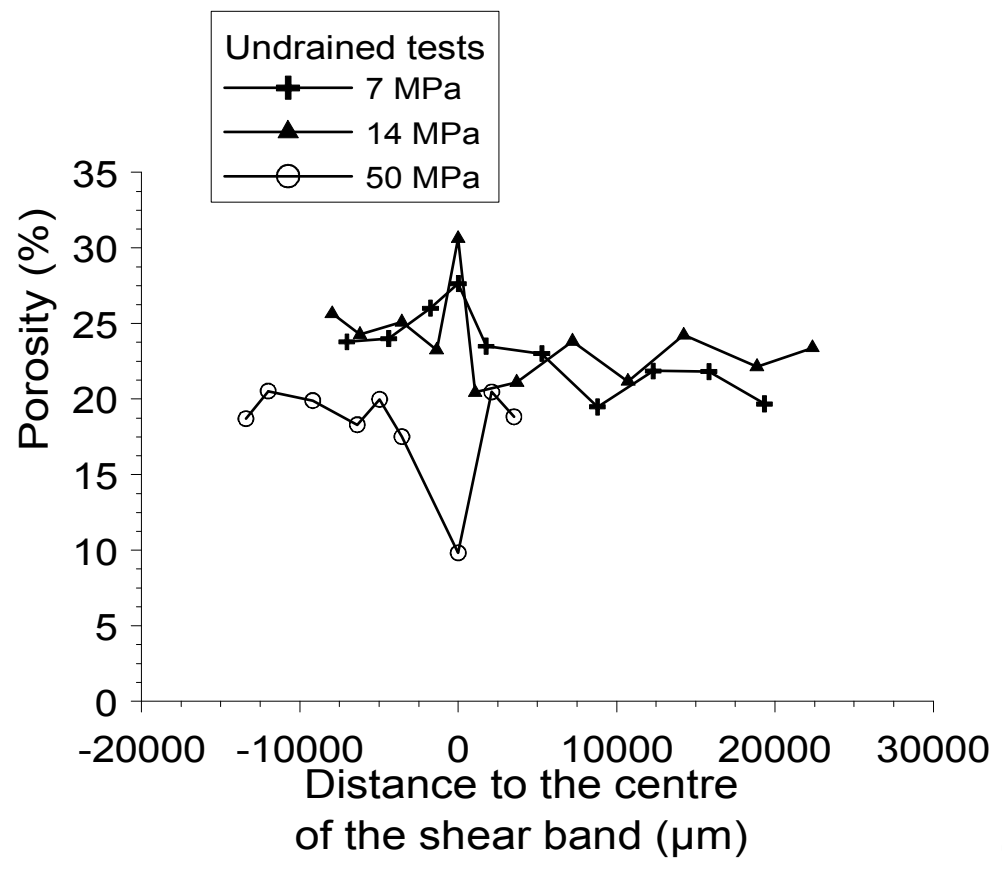

(b)

Fig. 21: Porosity evolution in the direction perpendicular to the major (in absolute value) principal stress axis: (a) drained tests; (b) undrained tests 


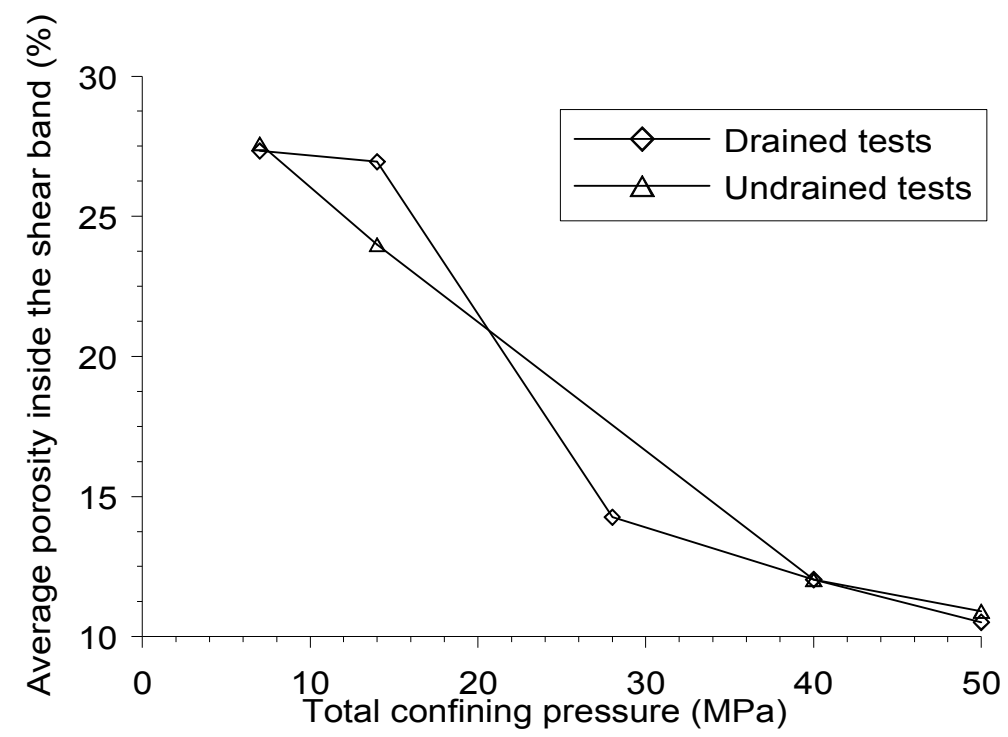

Fig. 22: Average porosity evaluated inside the shear band for drained and undrained tests 


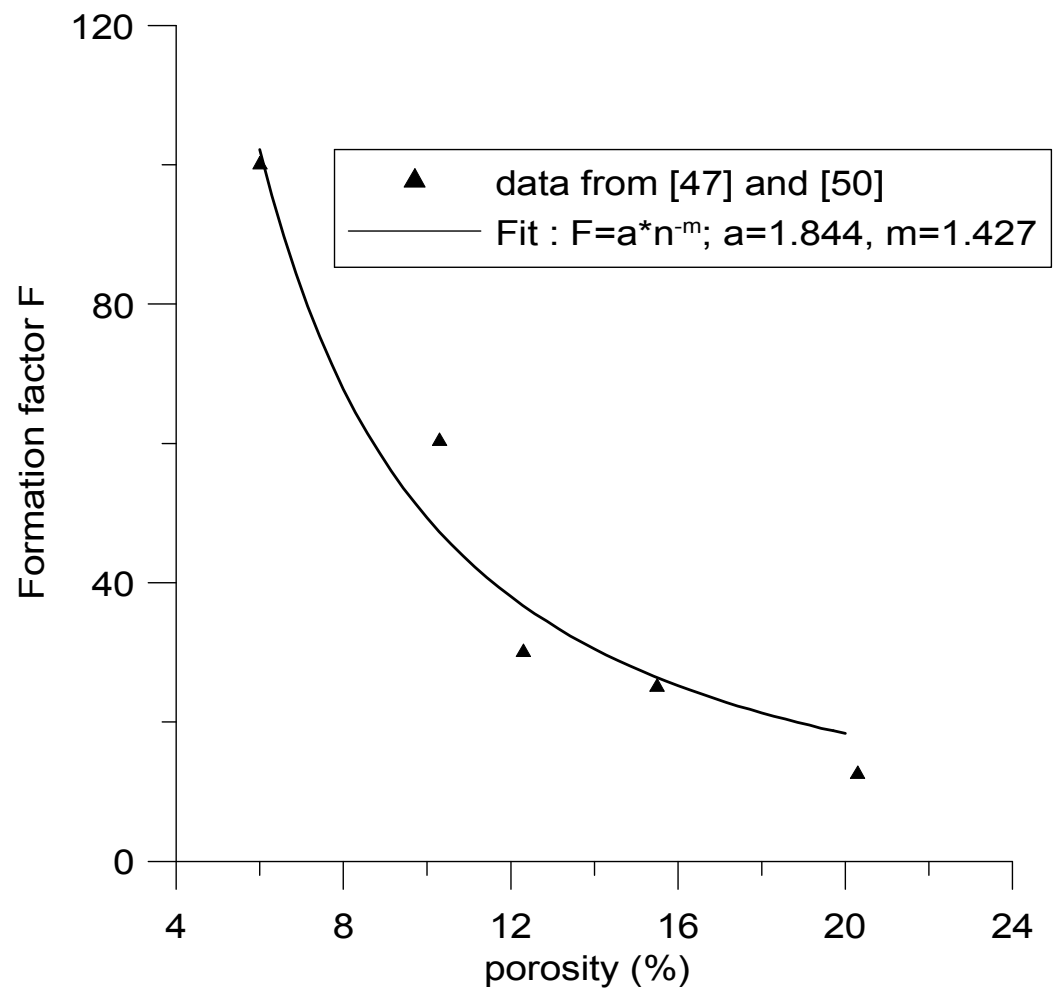

Fig. 23: Evaluation of the formation factor 


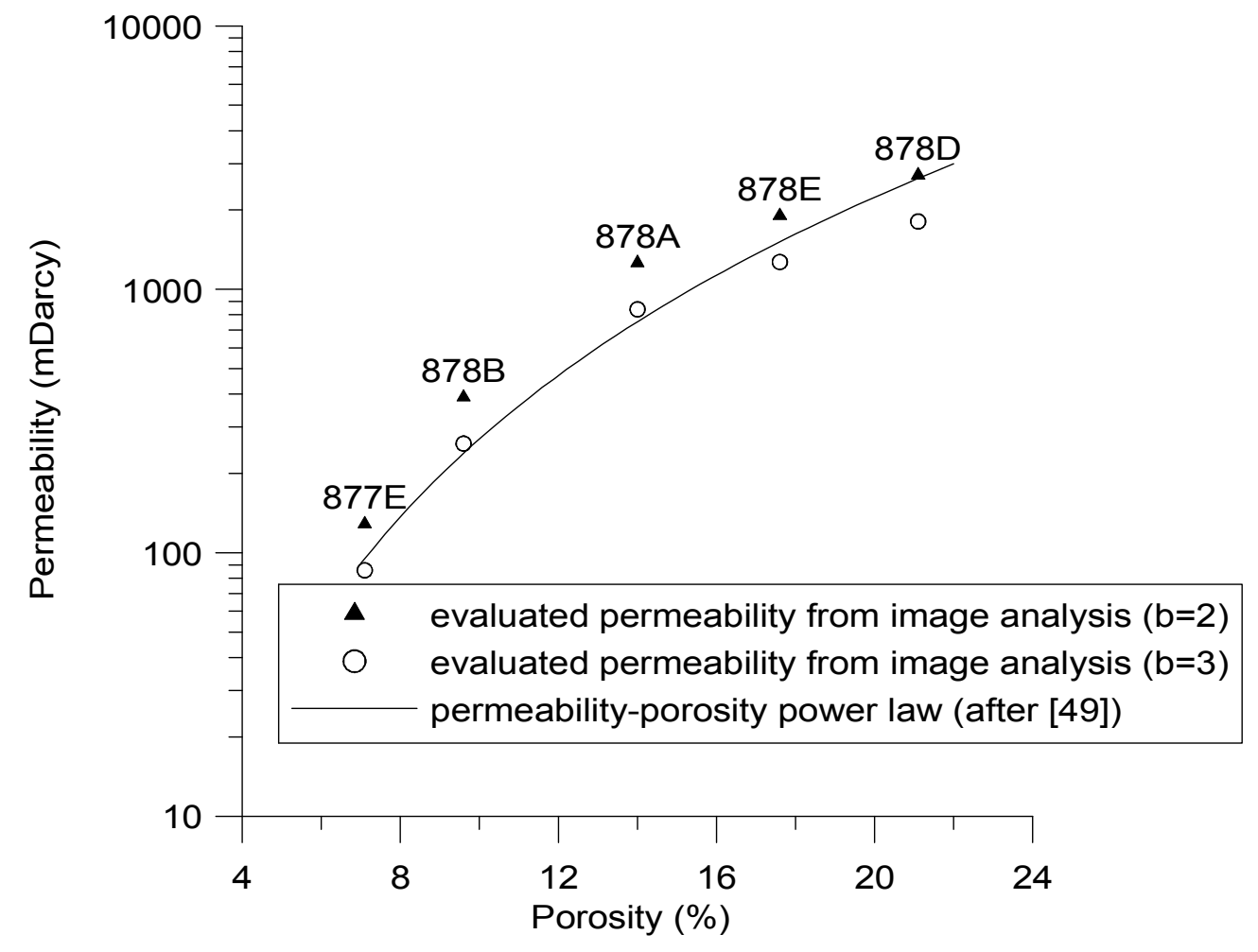

Fig. 24: Permeability evaluation on intact samples and comparison with Bourbier and Zinsner [49] power law 

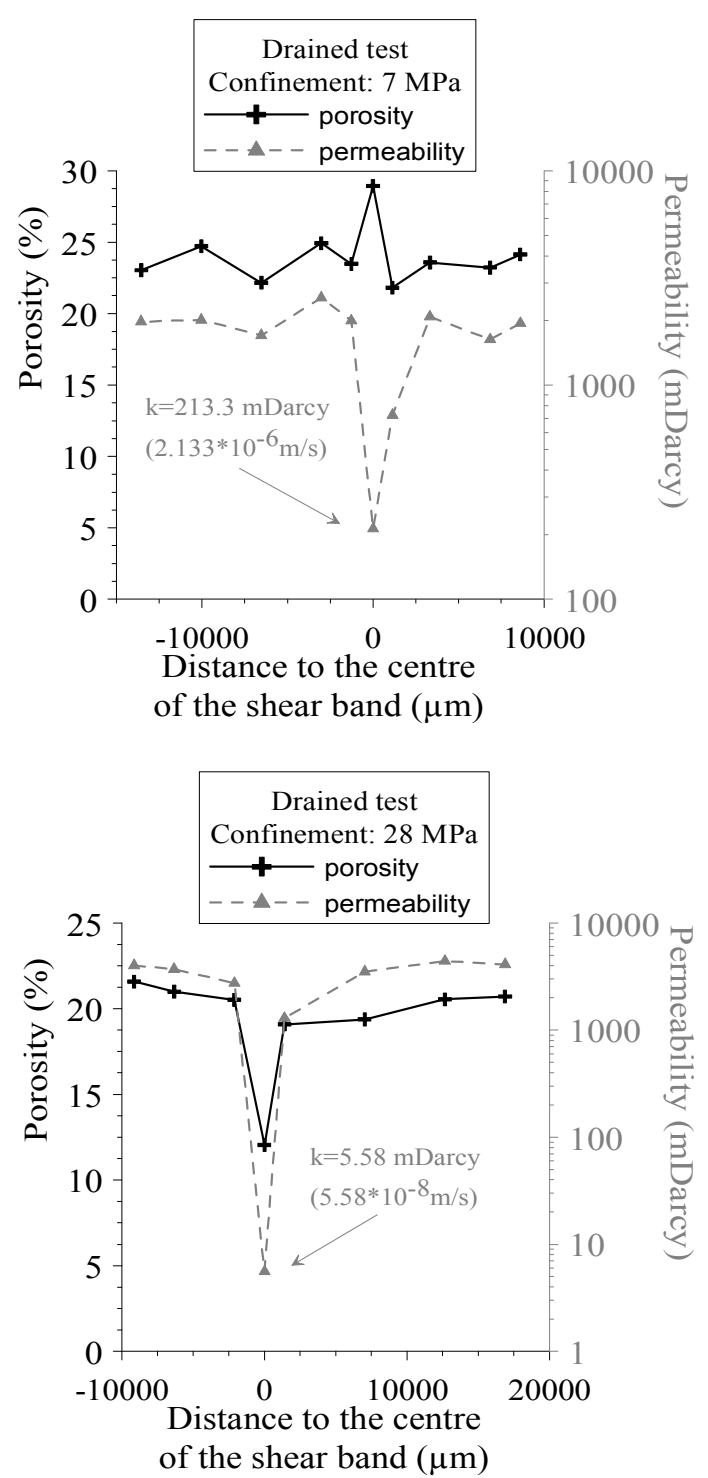
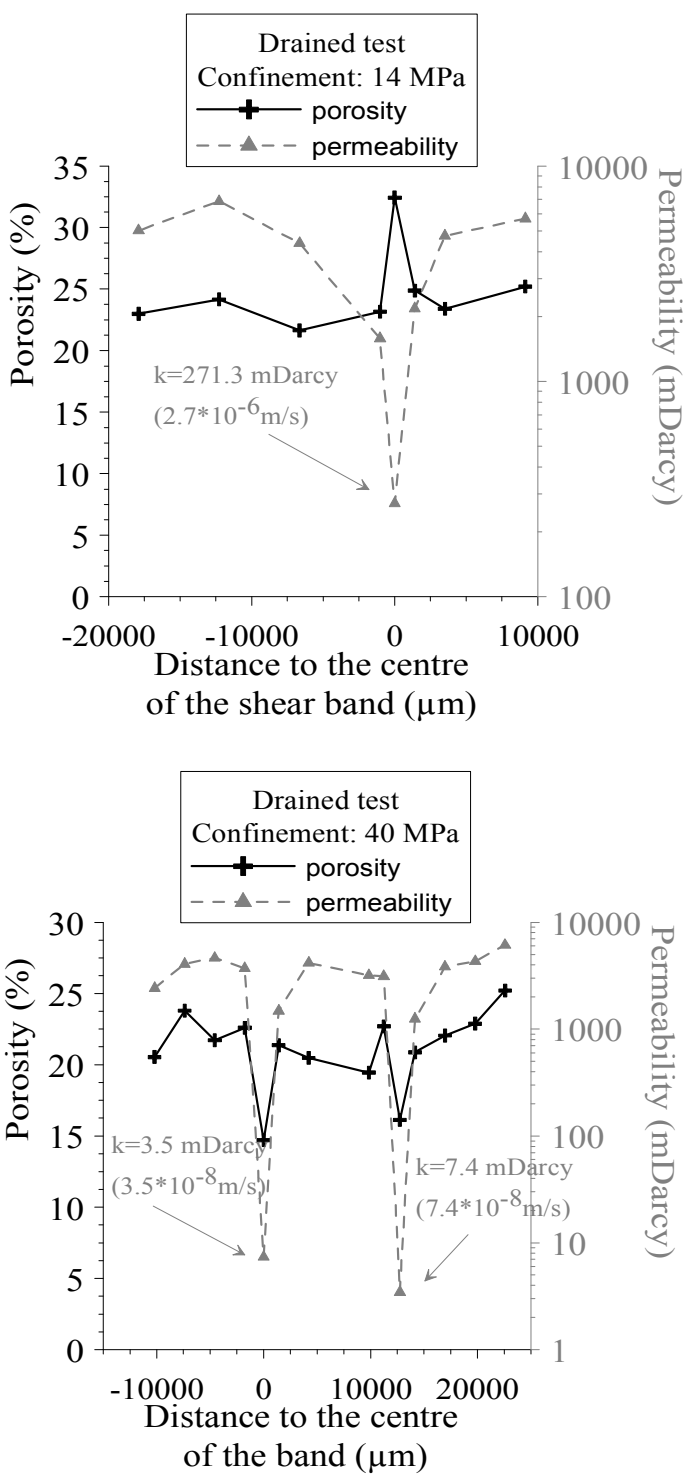

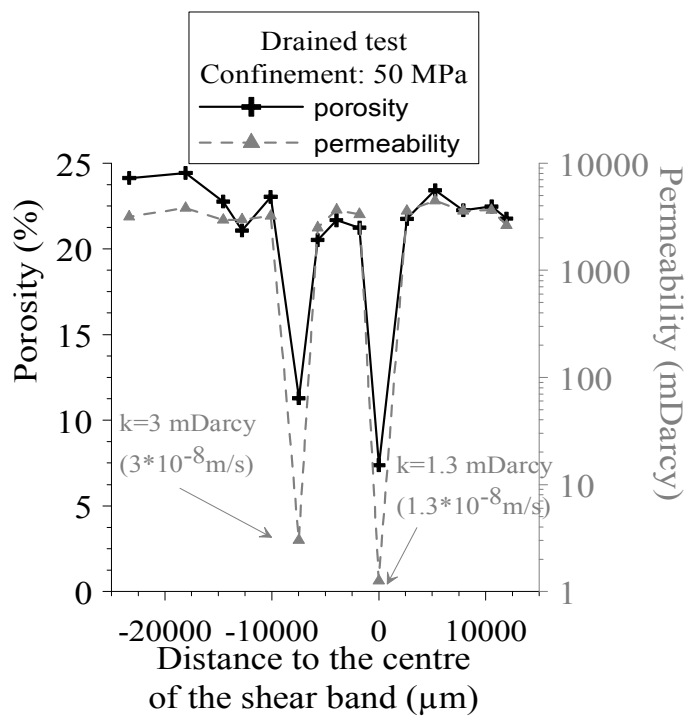

Fig. 25: Evaluation of the permeability inside the shear bands for drained tests 

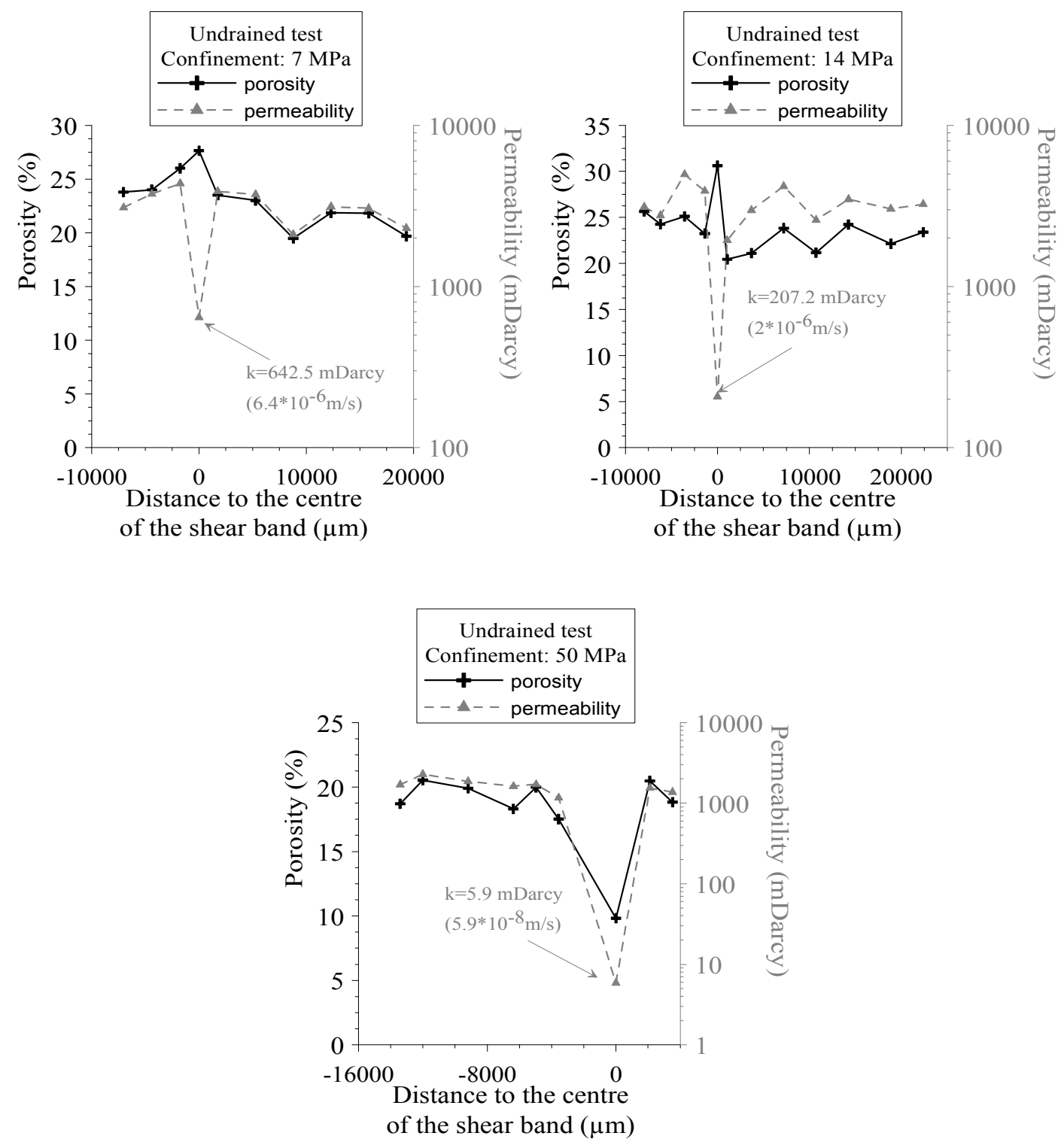

Fig. 26: Evaluation of the permeability inside the shear bands for undrained tests 


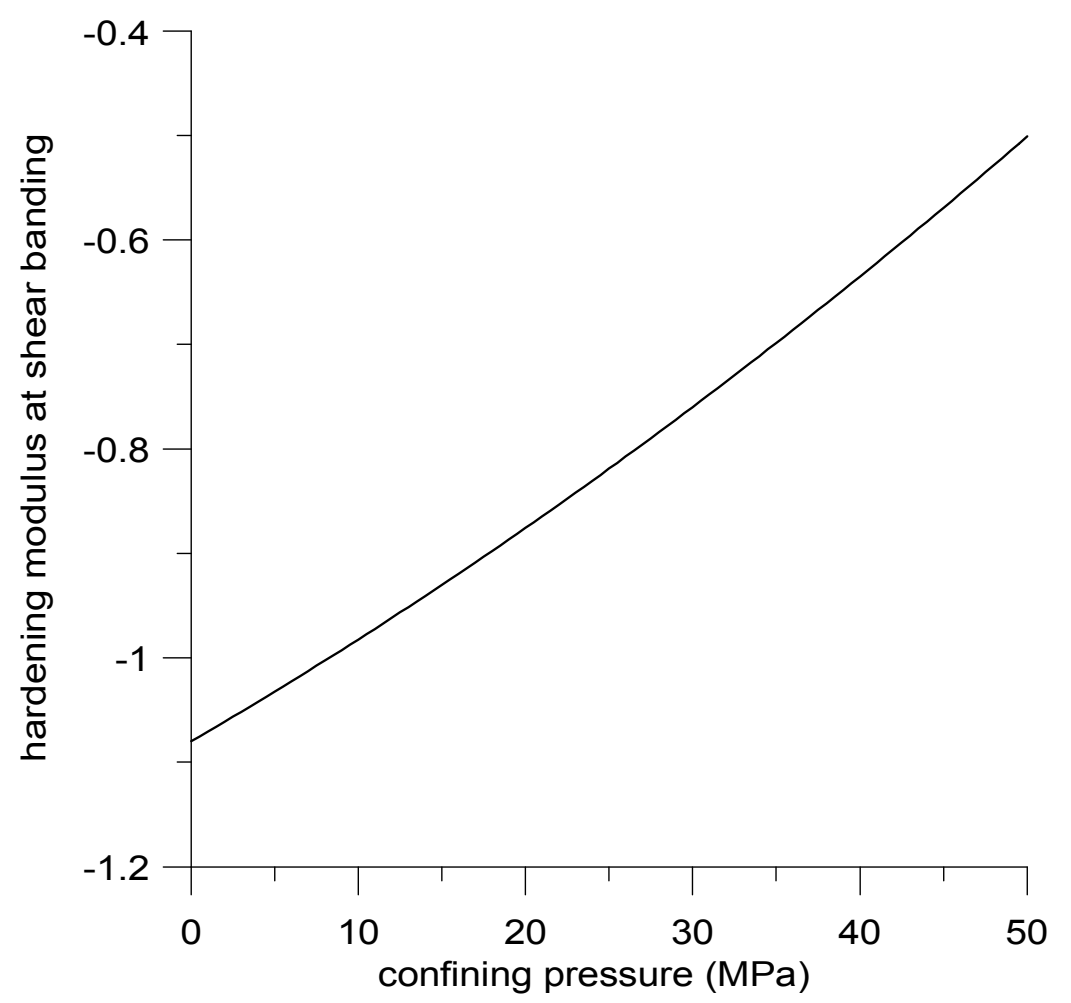

Fig. 27: Critical hardening modulus at shear banding 


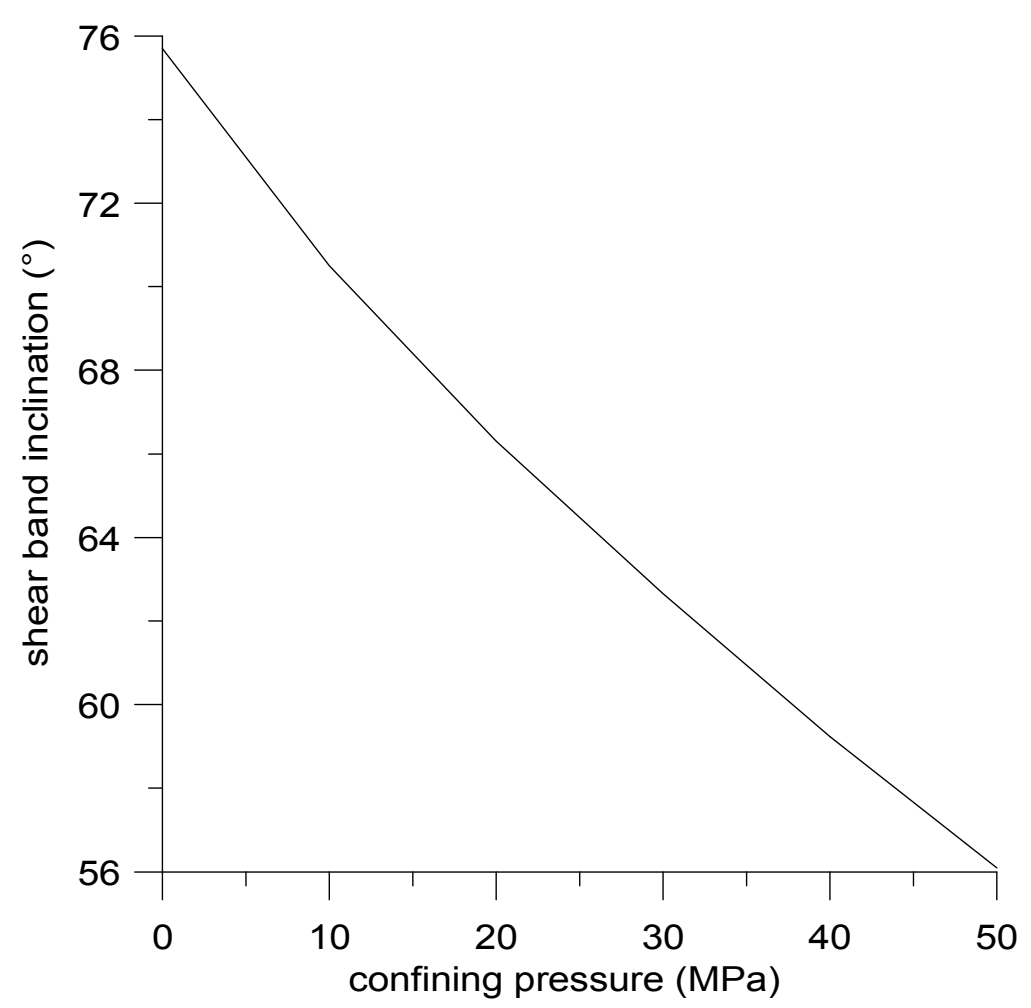

Fig. 28: Computed shear band inclination 